ESTUDIO

\title{
POLÍTICA COMERCIAL ESTRATÉGICA EN EL MERCADO AÉREO CHILENO ${ }^{1}$
}

\author{
Ronald Fischer
}

En este trabajo se estudia la política comercial en el transporte aéreo desde un punto de vista estratégico. En particular, se examinan las condiciones bajo las cuales es apropiada una política de reciprocidad (a diferencia de una apertura unilateral). La política de reciprocidad se basa en la idea de que el país con el que se negocia un acuerdo estará más dispuesto a ofrecer abrir su mercado aerocomercial si obtiene algo a cambio. En este trabajo se demuestra que la política de reciprocidad es preferible a la apertura unilateral si se cumplen ciertas condiciones de mercado: existencia de alternativas para los vuelos entre los puntos, la existencia de varias firmas compitiendo intensamente, y si el costo de esperar una resolución positiva es bajo. En el caso de países con los que no hay acuerdos de cielos abiertos se estima en forma aproximada el aumento en el bienestar social proveniente de una frecuencia adicional. Se obtiene un valor de varios millones de dólares, de los cuales entre 30 y $40 \%$ corresponde a mayores utilidades para la firma doméstica.

Ronald Fischer. Ph. D. en Economía, University of Pennsylvania. Ingeniero Civil Matemático, Universidad de Chile. Profesor-investigador del Centro de Economía Aplicada (CEA), Depto. Ingeniería Industrial de la Universidad de Chile.

${ }^{1}$ Este trabajo recibió el apoyo de la Junta de Aeronáutica Civil (JAC) y del Instituto Sistemas Complejos de Ingeniería. Las opiniones y posibles errores en este estudio son míos y no representan la opinión de la JAC.

Estudios Públicos, 109 (verano 2008). 


\section{Introducción}

ـ os mercados aeronáuticos internacionales no son perfectamente competitivos, debido a que los países imponen diversas restricciones al uso de los cielos por empresas extranjeras. Estas restricciones, cuyo origen es netamente proteccionista, limitan tanto las frecuencias de vuelos entre rutas (pares de origen-destino), así como el valor que tienen estas frecuencias al imponer condiciones limitantes a los vuelos entre los dos puntos².

En el caso de la aviación comercial existen dos motivaciones para el proteccionismo. En primer lugar, persiste la idea de que la aviación es un área con alcances estratégicos, lo cual la diferencia de otras áreas y requiere de una intervención estatal especial. Segundo, se utilizan argumentos de transferencia de renta en mercados aéreos que operan bajo competencia imperfecta, por lo que ofrecer condiciones equitativas puede conducir a una pérdida de excedente social. El problema, como es bien sabido por los estudiosos del comercio internacional, es que este tipo de argumentos los utilizan siempre los grupos de presión que desean proteccionismo, independientemente de su validez, por lo que es necesario determinar si resultan apropiados o no. En este trabajo no me referiré a los argumentos estratégicos (militares) para proteger a la aviación comercial ${ }^{3}$. El trabajo se concentra en los argumentos económicos para proteger el sector.

Un estudio del BID $^{4}$ para Sudamérica que examinó los convenios bilaterales al interior de la región, ha señalado que existe una asimetría al otorgar derechos entre los países del Norte y del Sur en América Latina que refleja el hecho que los mercados del Norte son considerados más valiosos. El argumento básico, por lo tanto, sería del tipo transferencia de renta, según el cual no se permite la entrada porque existe una renta de la que se apropian las empresas nacionales y que se perdería —o sería exportada al extranjero- si se permitiera que la firma extranjera operara sin restricciones.

Esto no es sólo una prerrogativa de países en desarrollo; por ejemplo, Estados Unidos restringe las aerolíneas extranjeras a unos pocos aeropuertos internacionales y no permite que operen en el país (Doganis, 1991). Esto puede parecer sorprendente, pues en otros aspectos de política comer-

\footnotetext{
${ }^{2}$ Estas limitaciones se denominan “libertades aéreas”, como se verá más adelante.

${ }^{3}$ Sin embargo, la lógica indica que si se determina que existen argumentos de defensa para proteger la aviación comercial, los costos de este proteccionismo para los usuarios de la aviación comercial deberían ser incorporados en el presupuesto de las Fuerzas Armadas de manera de reflejar fielmente el costo de esta contribución a la defensa nacional. ${ }^{4}$ BID: “Estudio de Integración del Transporte Aéreo en Sudamérica” (2003).
} 
cial Estados Unidos es un país relativamente abierto ${ }^{5}$. En otro ejemplo de esta dicotomía, EE.UU. permite la inversión extranjera en la mayoría de los sectores económicos sin restricciones, pero prohíbe el control de aerolíneas por extranjeros. En general, los países imponen restricciones cuantitativas y cualitativas a la "importación" de servicios aéreos 6 .

Desde un punto de vista económico, la aviación puede ser considerada como un servicio exportado por una firma de un país hacia otro y, por lo tanto, puede analizarse bajo la teoría del comercio internacional. La teoría más elemental del comercio internacional indica que, en presencia de mercados competitivos y sin externalidades, el bienestar se maximiza bajo libertad de comercio, que en el caso aéreo corresponde a la libertad irrestricta para establecer recorridos entre países. La teoría permite sólo dos excepciones al principio de no proteger un sector: cuando existen externalidades en la oferta del servicio y cuando existe competencia imperfecta en los mercados.

En el primer caso podrían existir economías de escala externas a la firma que pudiesen requerir protección temporal, del tipo a la industria naciente. Sin embargo, no parece apropiado aplicar este argumento a una industria madura como la aviación comercial, especialmente considerando que si existieran economías de escala, éstas probablemente serían internas a la firma, por lo que no es necesario establecer mecanismos de apoyo a la empresa $^{7}$. Otra posibilidad es que la aviación comercial produzca externalidades negativas, como, por ejemplo, de contaminación. En tal caso, la medida adecuada es un impuesto que lleve a que la aviación comercial internalice la externalidad, y no se debería discriminar entre firmas nacionales y extranjeras, ya que la contaminación es producida por todas las empresas $^{8}$.

La otra excepción a la regla de no intervenir en los mercados ocurre cuando el mercado en cuestión no es competitivo. Pese a que los mercados aéreos pueden llegar a ser bastante competitivos, persisten las imperfecciones. Esto se ha demostrado en el competitivo mercado de los EE.UU. al intentar verificar empíricamente la predicción de la teoría de los mercados desafiables (Baumol et al., 1982), que el temor a la entrada de competencia en la industria aérea mantendría los precios a nivel de costos medios. Morri-

\footnotetext{
${ }^{5}$ Pueden existir razones históricas: en EE. UU. el cabotaje marítimo está restringido desde hace más de doscientos años a naves de bandera nacional, y puede ser que las restricciones al transporte aéreo sea una simple transposición de esta restricción al mundo aéreo.

${ }^{6}$ Más detalles de la política comercial en los mercados aéreos, en Doganis (1991).

${ }^{7} \mathrm{Al}$ ser economías internas a la empresa, la empresa se beneficia totalmente de ellas, por lo que no deberían impedir su desarrollo. Éste es un argumento conocido de la Teoría de Comercio Internacional. Ver, por ejemplo, Krugman (1988).

${ }^{8}$ Un artículo reciente sobre contaminación producida por la aviación comercial es “The Sky is the Limit”, The Economist, junio 8, 2006.
} 
son y Winston (1987), entre otros, demostraron que para reducir los precios en las rutas era mucho más importante la competencia efectiva o presencial que la posibilidad de competencia ${ }^{9}$.

Considerando que incluso en mercados nacionales de Estados Unidos la competencia potencial mantiene precios sobre los de competencia, salvo en los mercados con mucha competencia presencial, es razonable pensar que los mercados internacionales del transporte aéreo, en los cuales intervienen los Estados, la competencia sería aun menos efectiva en disipar rentas. Debido a que los mercados del transporte aéreo por lo general son oligopólicos o monopólicos, la transferencia de rentas entre los países es un ítem relevante ${ }^{10}$. La posibilidad de transferir rentas económicas puras al extranjero puede justificar el uso de estrategias distintas de la apertura unilateral, como ha sido analizado en la teoría de la política comercial estratégica ${ }^{11}$. Además, debido precisamente a la existencia de estas rentas, hay lobbies poderosos que objetan la introducción de competencia en el transporte aéreo. El resultado es una política comercial más restrictiva que en otros sectores.

En este contexto, la política chilena general es de apertura, reconociendo los beneficios de una reducción en los costos de transporte que obtiene un país pequeño y alejado de sus mercados principales. Su política consiste en el

[...] libre mercado, en virtud del cual la regulación de la oferta de servicios aéreos quedó entregada al libre juego de la oferta y de la demanda, pudiendo, en principio, operar libremente todos aquellos transportadores aéreos que cumplan con requisitos de orden técnico y de seguros.

El tráfico internacional debió quedar igualmente abierto para todos los transportadores, nacionales y extranjeros. Sin embargo, al existir Estados que protegen a sus empresas aéreas en los cielos de su territorio, la ley chilena faculta a la Junta de Aeronáutica Civil, por razones de reciprocidad y de restric-

${ }^{9}$ Los autores definieron competencia potencial en una ruta como la de aquellas aerolíneas que operaban en alguno de los aeropuertos, y competencia efectiva como la de aquellas aerolíneas que volaban entre los mismos puntos. Determinaron que un competidor efectivo tenía el mismo resultado en la reducción de precios que tres competidores potenciales.

${ }^{10}$ Aunque la ausencia de competencia a menudo se debe a la intervención de los Estados, aquí no se puede aplicar la receta de Stigler (1971) de tener como primera opción la eliminación de la distorsión regulatoria, porque eso requiere la cooperación de dos gobiernos y no sólo de uno, como en los casos analizados por Stigler.

${ }^{11}$ Brander (1995) tiene un análisis completo de la teoría de la política comercial estratégica. 
ción a transportadores chilenos, a terminar, suspender o limitar los servicios aéreos de transportadores extranjeros ${ }^{12}$.

La política de exigir reciprocidad en ocasiones es costosa, pues mientras el otro país no otorgue similares derechos, el mercado del transporte puede verse limitado en relación con una política de apertura unilateral, lo cual tiene un costo en términos de bienestar social. Más a menudo, la condición de reciprocidad puede inhibir las ofertas de negociación, por lo que tiene un efecto aun cuando formalmente no se invoca. Además, incluso en el caso de no existir reciprocidad, el costo social de esa política depende de las condiciones de competencia en los mercados en cuestión. De esta forma, el costo social de esperar una resolución más liberal en la contraparte (el otro país) debe balancearse con los beneficios que se obtienen de una liberalización asimétrica.

El objetivo de este trabajo es estudiar la optimalidad de diferentes políticas aerocomerciales, especialmente la de apertura con reciprocidad, en un contexto de competencia imperfecta. En general el método de análisis es similar al utilizado en la teoría del comercio estratégico, con algunas diferencias debido a la forma que toman las políticas de transporte aéreo ${ }^{13}$.

En el transporte aéreo, la intervención estatal se traduce en limitaciones a las frecuencias de vuelos en las rutas, o en limitaciones al valor que tienen los vuelos entre los destinos para las aerolíneas, introduciendo restricciones de operación (las que determinan las distintas libertades aéreas). Las políticas aerocomerciales se expresan mediante acuerdos bilaterales que especifican las frecuencias de vuelo entre los países (o entre ciudades de cada país), así como las libertades de que dispondrán esos vuelos, pudiéndose combinar libertades y frecuencias ${ }^{14}$. Por ejemplo, los vuelos a Brasil combinan la tercera y cuarta con la quinta y sexta libertades. El Cuadro $\mathrm{N}^{\mathrm{o}} 1$ de la sección 2 entrega una descripción de las distintas libertades. Desde el punto de vista de nuestro análisis, las restricciones al transporte aéreo no generan ingresos de tipo arancelario, lo que simplifica el análisis.

La metodología en este estudio será análoga a la utilizada en los modelos teóricos de comercio internacional estratégico, dado que el mercado de las líneas aéreas es oligopólico en la mayoría de los mercados interna-

12 Página web de la Junta de Aeronáutica Civil (JAC): http://www.juntade aeronauticacivil.cl/.

${ }^{13}$ Los instrumentos usuales de la teoría son los aranceles, subsidios y cuotas a las importaciones. Los subsidios no son el instrumento que se usa para sostener una línea aérea estatal ineficiente, como ocurre a menudo en el mercado aéreo, sino el instrumento por medio del cual se transfieren rentas hacia el país.

${ }^{14}$ Los países pueden firmar acuerdos de cielos abiertos, que eliminan muchas de estas restricciones, como se verá más adelante. 
cionales, y no es apropiado usar modelos diseñados para mercados competitivos $^{15}$. El análisis de comercio estratégico, basado a su vez en modelos de organización industrial, estudia los efectos de distintas políticas comerciales dependiendo del tipo de competencia y del número de participantes en el mercado. Estos modelos están asociados a los trabajos de Krugman, Brander y Spencer, Dixit, Eaton y Grossman, varios de los cuales están recopilados en Grossman $(1992)^{16}$.

Este esquema de análisis permitirá estudiar en forma teórica las condiciones bajo las que un país está mejor o peor con una apertura aerocomercial unilateral cuando la competencia es imperfecta, y las condiciones bajo las cuales es preferible establecer requisitos de reciprocidad. Una complicación es que el tipo de competencia entre aerolíneas no es evidente, pudiendo ser en precios, en cantidades (número de pasajes), o en capacidad combinada con precios. Para resolver este dilema usaré un modelo simple de variaciones conjeturales que puede describir todos los grados de competencia variando un solo parámetro ${ }^{17}$. Como lo sugiere Dixit (1986), pese a las críticas que se pueden hacer al modelo de variaciones conjeturales, tiene la ventaja de permitir tratar distintos tipos de competencia en un mismo marco teórico. Usando variaciones conjeturales se podrán determinar aquellos resultados que son independientes del tipo de competencia de aquellos que dependen de ésta.

\section{Acuerdos y regulaciones aeronáuticas}

Existen dos grandes grupos de regulaciones en las operaciones aéreas $^{18}$. Primero se encuentran una serie de estándares y normativas técnicas, cuyo objetivo es alcanzar altos niveles de seguridad. Se pueden dividir en:

1. Regulaciones sobre la seguridad de los aviones, no sólo en su diseño y estándares productivos sino también en su respuesta a distintos escenarios, como la pérdida de un motor.

${ }^{15}$ Agostini (2005) ha estudiado la estructura de la industria aérea en Chile y reconoce su carácter oligopólico, con una empresa dominante.

${ }^{16}$ Algunos de los artículos más importantes de esta área son Krugman (1987), Krugman (1981), Dixit y Norman (1981), Brander y Krugman (1983), Brander y Spencer (1985), Eaton y Grossman (1992).

${ }^{17} \mathrm{El}$ modelo de variaciones conjeturales supone que al maximizar en un juego estratégico, los jugadores elaboran “conjeturas” sobre las reacciones de los demás jugadores ante las acciones propias. Cada jugador maximiza considerando sus conjeturas, y, en el equilibrio, ningún jugador desea desviarse de su elección (normalmente esto genera conjeturas inconsistentes, la principal crítica al modelo).

${ }^{18}$ En esta parte del trabajo seguimos la exposición de Doganis (1991), capítulo 2. 
2. Reglas que cubren el mantenimiento y la reparación de las naves, y que se refieren a su periodicidad, naturaleza y supervisión, y al entrenamiento y certificación del personal que los llevan a cabo.

3. Normas sobre el número de miembros y el entrenamiento de la tripulación de cabina y de vuelo y sus obligaciones y estándares de horario.

4. Reglas detalladas de operación y procedimientos en las naves y las aerolíneas. Los transportistas deben estar certificados (de acuerdo a estándares de operación y otros criterios) en los países en los que operan.

5. Reglas adicionales que cubren estándares de aeropuertos, servicios meteorológicos, equipos de navegación, etc.

Gran parte de esta normativa es de carácter general y se aplica a todas las naves y aerolíneas, y normalmente las normativas de los países siguen las recomendaciones de la International Civil Aviation Organization (ICAO). La normativa más específica para cada tipo de nave está contenida en sus manuales de vuelo, los que quedan sujetos a los estándares generales y que deben ser aprobados por las autoridades nacionales ${ }^{19}$.

Además de esta normativa técnica, existe un gran número de limitaciones al transporte aéreo que tienen objetivos económicos y que tienden a diferenciar entre aerolíneas de acuerdo a la nacionalidad de sus propietarios. Este segundo grupo de reglamentaciones comenzó con la Convención de París de 1919, que estableció el principio de que cada país tenía derechos soberanos sobre su espacio aéreo, lo que implicaba, en forma natural, la intervención de los gobiernos en el transporte aéreo. Así, la libertad de los cielos anterior a 1919 fue reemplazada por acuerdos bilaterales entre países con aerolíneas y con aquellos países por los cuales debían pasar los vuelos. La complejidad de estos acuerdos condujo a que, en 1944, se reunieran en Chicago 52 países para establecer un acuerdo multilateral que reglara:

1. el intercambio de derechos de vuelo, o libertades;

2. el control de tarifas de pasajes y carga;

3. el control de frecuencias y capacidades.

La Convención enfrentó un conflicto entre dos propuestas. Estados Unidos deseaba una libertad (casi) total: sin control de tarifas o capacidades, y el máximo intercambio de quintas libertades (ver Cuadro $\mathrm{N}^{\circ} 1$ para

\footnotetext{
${ }^{19}$ Estos manuales, además de estándares de mantenimiento y operación específicos, contienen limitaciones a la carga para distintas altitudes, o de acuerdo a la temperatura ambiente.
} 
una descripción de las distintas libertades). Esta política reflejaba el hecho que EE.UU. terminaba la guerra con su aviación civil indemne. Su posición fue apoyada por países pequeños como Holanda y Suecia, cuyos mercados internos no eran lo suficientemente atractivos como para defenderlos. La otra posición era la que tenían los demás países europeos, que habían sido devastados por la guerra. Ellos preferían un mercado estrictamente regulado, en tarifas, capacidad y libertades aéreas. El desacuerdo impidió un arreglo multilateral, salvo en el intercambio mutuo de las dos primeras libertades (de sobrevuelo y a realizar escalas técnicas), pero no hubo acuerdo en las libertades con contenido comercial. La Convención de Chicago pudo al menos establecer la ICAO y los estándares asociados a esa organización. Desde 1944 el intercambio de libertades es un proceso bilateral entre países.

En 1945 se fundó la International Air Transport Organization (IATA), cuyo rol era representar los intereses de las líneas aéreas ante la ICAO. Entre otras cosas, estandarizó procedimientos y operaciones en las líneas aéreas y estableció un clearing house para netear las deudas entre líneas aéreas que se generan cuando una línea transporta pasajeros de otras empresas. Además, la IATA servía como un mecanismo para cartelizar el mercado aéreo internacional, estableciendo tarifas para pasajeros y carga, así como complejas reglas para evitar la competencia por calidad, que podría ayudar a disipar las rentas ${ }^{20}$. Por último, el tarifado y conjunto de reglas debía ser aprobado por consenso. El cartel disponía de inspectores que fiscalizaban que las líneas aéreas no ofrecieran descuentos no estipulados, los que podían significar fuertes multas a la empresa que se descubría que violaba las reglas. Este cartel comenzó a desarmarse con la entrada de las aerolíneas charter, que no tenían frecuencias aseguradas y, por lo tanto, no necesitaban ajustarse a las reglas de la IATA. Más tarde, durante la administración Carter, comenzó un proceso de desregulación de la industria aérea interna en los Estados Unidos que posteriormente se extendió a los mercados internacionales. Luego de dos décadas de proceso de desregulación en el mundo (muy resistido originalmente) la IATA ha perdido su rol en el proceso de fijación de tarifas y en la cartelización de la industria ${ }^{21}$.

Luego de dejar su rol como agente cartelizador, la IATA ha perdido importancia. En el proceso de cambio hacia una estructura más competitiva en el transporte aéreo internacional, la industria sufrió profundos cambios

\footnotetext{
${ }^{20}$ La IATA establecía reglas sobre el ángulo de los asientos, el número de comidas en un vuelo, el cobro por los audífonos, etc.

${ }^{21}$ La desaparición de IATA como cartel explica que, hasta la reciente alza en los precios del petróleo, las tarifas aéreas hayan bajado en dólares nominales desde la década de los 80, pese a la inflación acumulada desde entonces.
} 
CUADRO No $1: \quad$ LIBERTADES AÉREAS

$\begin{array}{ll}\text { Libertad } & \text { Derechos otorgados } \\ \text { Primera libertad } & \begin{array}{l}\text { Derecho a sobrevolar el territorio del país contraparte (B) sin ate- } \\ \text { rrizar. }\end{array}\end{array}$

Segunda libertad Derecho a aterrizar en el territorio del país contraparte (B) sin fines comerciales (escala técnica).

Tercera libertad Derecho a llevar pasajeros desde el propio país (A) hacia el país contraparte (B).

Cuarta libertad Derecho a traer pasajeros desde el país contraparte (B) hacia el país propio (A).

Quinta libertad Derecho de transportar pasajeros entre el país contraparte (B) y un tercer país (C), pero solamente en vuelos originados en el país propio (A). El derecho es válido para transportar pasajeros en ambas direcciones. Para poder ejercer este derecho, se requiere contar con el mismo derecho otorgado por parte del país " $\mathrm{C}$ ”.

Sexta libertad Derecho de transportar pasajeros entre el país contraparte (B) y un tercer país (C), pero pasando (tránsito) por el país propio (A). El derecho es válido para transportar pasajeros en ambas direcciones. Para poder ejercer este derecho, se requiere contar con el mismo derecho otorgado por parte del país "C". Muchos países ejercen el derecho de sexta libertad combinando una cuarta libertad por parte del país "B" con una tercera libertad obtenida por parte del país "C".

Séptima libertad Derecho de transportar pasajeros entre el país contraparte (B) y un tercer país (C), pero sin necesidad de utilizar un vuelo originado en el país propio (A). Este derecho es idéntico a la quinta libertad, pero libera la restricción de iniciar el vuelo en el país propio. El derecho es válido para transportar pasajeros en ambas direcciones. Para poder ejercer este derecho, se requiere contar con el mismo derecho otorgado por parte del país "C".

Octava libertad Derecho a transportar pasajeros entre puntos dentro del territorio del país contraparte (B), pero como continuación de un vuelo originado en el país propio "A".

Novena libertad Derecho a transportar pasajeros entre puntos dentro del territorio del país contraparte (B), sin restricciones de origen del vuelo. 
con la desaparición de las líneas más tradicionales y la aparición de líneas de bajo costo cuya existencia puede ser efímera. Las antiguas líneas aéreas nacionales han desaparecido en casi todo los países, o han sido privatizadas. En los pocos casos en que esto no ha ocurrido, los gobiernos han tenido que inyectar sumas importantes cada cierto número de años, ya que la competencia es demasiado intensa para las pesadas estructuras de estas empresas estatales.

Pese a los avances, las restricciones a la libertad de vuelos persistían en muchos países desarrollados hasta fines de los $90^{22}$. Hacia la mitad de la década persistían casi 3.000 acuerdos bilaterales que especificaban los derechos de tráfico aéreo entre dos países ${ }^{23}$.

A comienzos de los 90, Estados Unidos comenzó a proponer una política de acuerdos bilaterales de cielos abiertos. En ellos no se limitaba el número de aerolíneas (en cada país) que podían participar en el acuerdo, se eliminaban las restricciones de capacidad y frecuencia, permitiéndose el cambio de tipo de aeronave, se otorgaban la quinta y sexta libertad, y había casi total libertad tarifaria. Estos acuerdos no implican la competencia internacional total, ya que las aerolíneas aún debían ser designadas por los gobiernos respectivos, no se liberalizaban las inversiones desde el otro país, ni se otorgaban la séptima y octava libertad (que permiten operar entre dos países sin necesidad de que el vuelo parta o termine en el país de donde proviene la aerolínea), que son esenciales para la optimización de las redes aéreas. Estas restricciones obedecen a una política de Estados Unidos, que siempre ha sido reticente a la participación de inversionistas de otras naciones en sus aerolíneas domésticas.

Más recientemente aún, han aparecido los Mercados Aéreos Regionales (MAR), que son los equivalentes en la aviación comercial a las uniones aduaneras en el comercio internacional. Los MAR consideran la liberalización del cabotaje doméstico, la séptima y octava libertad entre países integrantes del mercado, las inversiones cruzadas y la libre entrada al mercado aéreo, además de las condiciones ya establecidas en los acuerdos de cielos abiertos. Los casos más interesantes son el MAR entre Australia y Nueva Zelanda y el de Europa con el European Single Aviation Market.

\footnotetext{
${ }^{22}$ Ver Gönenç y Nicoletti (2001).

${ }^{23}$ En ellos se describen en detalle las rutas aéreas (asociadas a las mínimas libertades para la operación comercial, tercera y cuarta), las aerolíneas autorizadas, los tipos de naves autorizadas y sus frecuencias así como el tipo de tarifas que eran aplicables. En particular, en muchos casos se requería la autorización de ambos países para ofrecer un nuevo tarifado.
} 


\section{Antecedentes del mercado chileno}

El mercado aéreo chileno tiene dos componentes, el cabotaje nacional y los vuelos internacionales. Los pasajeros internos han crecido lentamente debido a las consecuencias de la crisis asiática en 1997. Su crecimiento interno fue de 3,1\% anual entre 1996 y 2005, año en el que se transportaron a casi tres millones doscientos mil pasajeros, un $77 \%$ de ellos en Lan ${ }^{24}$. En el mercado de vuelos internacionales, el crecimiento ha sido mayor, pues registró un incremento anual de 5,8\% en el mismo período, hasta llegar a casi cuatro millones de pasajeros (entre llegadas y salidas). En este mercado, Lan ha elevado su participación desde un 42\% en 1996 a un 57\% en 2005, y ha sido básicamente el único operador internacional chileno. En el mercado de la carga internacional, que ha llegado a ser un factor relevante en el comercio internacional de nuestro país, la carga de salida ha crecido lentamente (2,3\% anual) en el período 1996-2002, hasta alcanzar a 144 mil toneladas. Lan es el único operador chileno con un 51\% de participación. En la carga de entrada el crecimiento ha sido más rápido, con una tasa anual de 5,9\% en el período, pues alcanzó las 102 mil toneladas. Lan posee el 53\% de la carga de entrada internacional. Salvo en el cabotaje nacional -en que Lan domina el mercado con su 70\% de participación-, en los demás mercados aéreos es el único operador nacional. De acuerdo con las definiciones de la OECD, se trata de un mercado relativamente poco competitivo, como se verá en la próxima sección, que examina los mercados aéreos de la OECD.

\section{Estructura aerocomercial en los países de la OECD ${ }^{25}$}

Un reciente análisis de la OECD (Gönenç y Nicoletti, 2001) revisa la estructura industrial de los mercados aéreos de los países miembros. El estudio determina que todavía hay pocas rutas internacionales de larga distancia efectivamente competitivas. Esto impide la creación de un mercado aéreo mundial y genera redes de transporte aéreo subóptimas. Pese a los avances que representan los mercados aéreos regionales (véase supra) y las políticas de cielos abiertos, éstos no permiten la entrada de aerolíneas pertenecientes a países externos a los acuerdos, por lo que sólo representan una liberalización parcial. El estudio observa que en la mayoría de los merca-

\footnotetext{
${ }^{24}$ Este porcentaje nunca bajó de 70\% en el período y llegó a alcanzar un 95\% en 2002.

${ }^{25}$ La información de esta sección proviene de Gönenç y Nicoletti (2001).
} 
dos de la OECD y en la mayoría de las rutas entre ellos, la concentración del mercado es significativa y sólo unas pocas aerolíneas ofrecen sus servicios. A menudo, esto se debe a la presencia de un operador de bandera (flag carrier), con frecuencia controlado por el gobierno. En otros casos se han formado alianzas entre las líneas aéreas dominantes, lo que reduce aún más la competencia. Un factor que contribuye a los problemas de competencia son las dificultades para encontrar slots en los aeropuertos, especialmente debido a que en muchos de ellos una aerolínea controla más del 50\%. Estos problemas de competencia no están ausentes en el caso chileno.

El artículo citado muestra que la eficiencia productiva y las tarifas se ven afectadas por las restricciones regulatorias y por las imperfecciones de los mercados aéreos. Tal como lo predice la teoría, la eficiencia y la tasa de ocupancia tienden a elevarse y las tarifas tienden a caer cuando el mercado y las regulaciones son más proclives a la competencia. La evidencia sugiere además que las tarifas de clase turista suben en aquellas rutas dominadas por alianzas entre aerolíneas. Además, el estudio muestra la existencia de una sinergia entre la desregulación y la competencia efectiva en las rutas, ya que la competencia potencial (permitida por la liberalización de las regulaciones) no elimina las imperfecciones del mercado.

En resumen, los resultados del estudio de Gönenç y Nicoletti (2001) confirman que las reformas que liberalizan la entrada a los mercados aéreos y promueven la competencia proveen beneficios significativos a todas las categorías de pasajeros. Las figuras siguientes presentan algunos de los resultados del estudio, los que caracterizan el grado de competencia en el mercado aéreo de la OECD en los años 95-96. La Figura $\mathrm{N}^{\circ} 1$ muestra a los países de la OECD ordenados de acuerdo al grado de liberalidad de sus políticas comerciales y al grado de competencia en sus mercados. La variable regulatoria en las ordenadas de la figura es un índice (en que un valor menor indica más competencia) que reúne el tipo de políticas internas y externas en los mercados aéreos del país, la participación del gobierno en las aerolíneas (subsidios, participación accionaria, obligaciones de servicio público) y el tiempo desde la liberalización regulatoria. Las variables referidas a la estructura de mercado consideran la cantidad de rutas que son servidas por más de tres aerolíneas, el índice de Hehrfindahl del mercado, la participación del mercado internacional de la mayor firma nacional, y variables similares a nivel de rutas específicas. Claramente, Estados Unidos seguido de Holanda y el Reino Unido son los países con los mercados más competitivos. 
FIGURA N ${ }^{\circ}$ 1: $\quad$ INDICADORES REGULATORIOS Y DE COMPETENCIA, EN ORDEN DE ANTICOMPETITIVIDAD

- Condiciones de mercado

$\square$ Presencia de un operador de bandera

$\square$ Apertura de las regulaciones internacionales

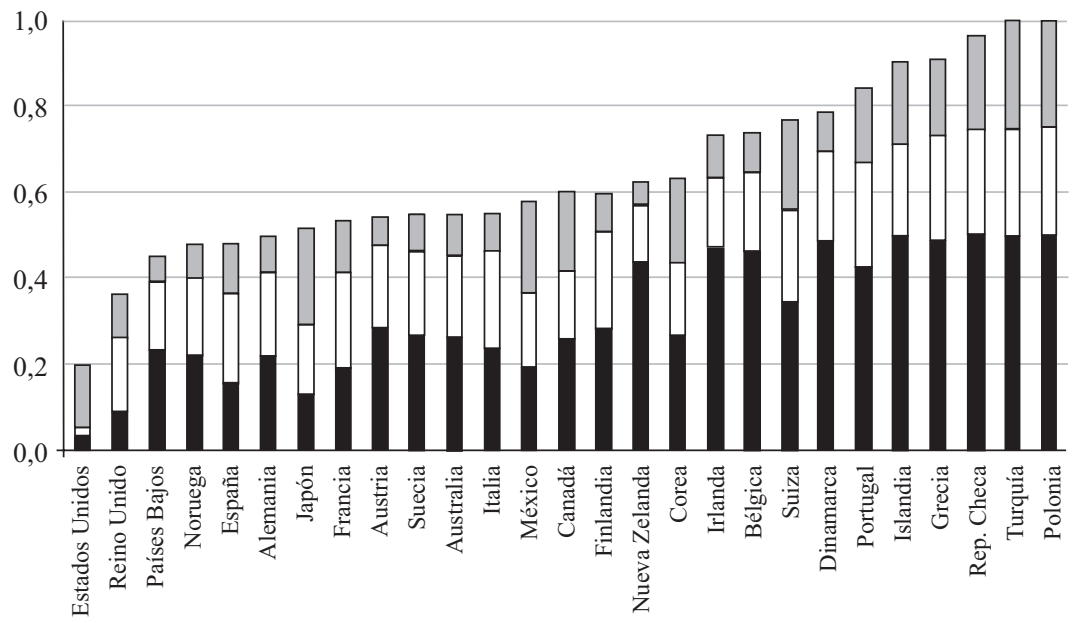

Fuente: Göneç y Nicoletti (2001), reproducida con la debida autorización.

Las Figuras $N^{\text {os }} 2$ a 4 muestran estas variables a nivel de rutas específicas (denotadas por origen y destino), las que están indicadas en las abcisas. La Figura $\mathrm{N}^{\circ} 2$ muestra un indicador global del grado de competencia en la ruta, y las otras dos figuras muestran dos de los factores más importantes en el indicador general de competencia. Normalmente, los factores están correlacionados, de manera que las rutas con menos regulaciones son también las que tienen alta competencia.

Las Figuras $\mathrm{N}^{\circ} 5$ y N $\mathrm{N}^{\circ}$, también del estudio de Gönenç y Nicoletti (2001), muestran que la competencia y regulaciones más liberales aumentan la eficiencia en la industria aerocomercial. La Figura $\mathrm{N}^{\circ} 5$ muestra que los países con menos regulaciones y mayor competencia tienen aerolíneas que están más cercanas a la frontera de la eficiencia productiva (de acuerdo a la metodología conocida como data envelopment analysis). Por su parte, la Figura $\mathrm{N}^{\mathrm{o}} 6$ muestra que los mercados con menos regulaciones y mayor competencia son aquellos en que los vuelos tienen un uso más eficiente, ya que tienen una mayor tasa de ocupación. La conjunción de una mayor eficiencia productiva y la mayor ocupación debido al ambiente más competitivo se traduce en menores tarifas para los usuarios. 
FIGURA N ${ }^{\circ}$ 2: $\quad$ APERTURA A LA COMPETENCIA DE RUTAS ESPECÍFICAS

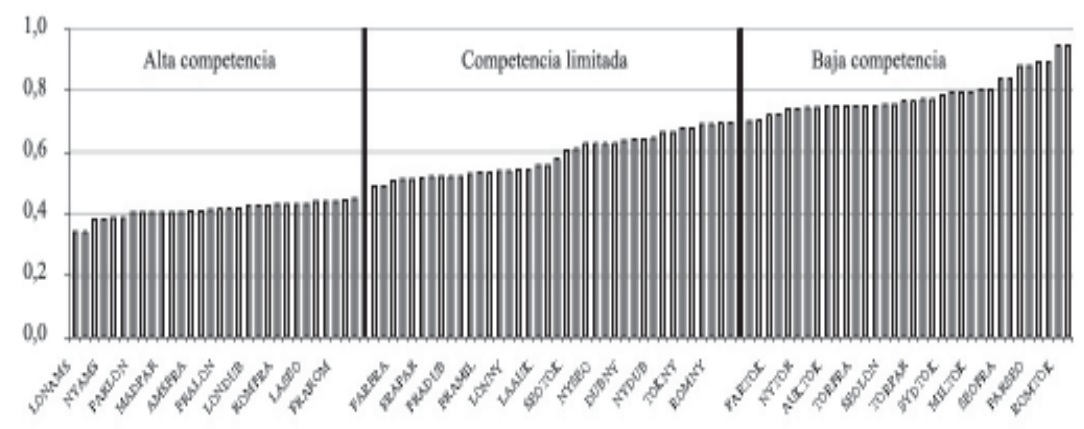

Fuente: Göneç y Nicoletti (2001), reproducida con la debida autorización.

FIGURA N ${ }^{\circ}$ 3: $\quad$ PROPENSIÓN A LA COMPETENCIA EN LA REGULACIÓN DE RUTAS ESPECÍFICAS

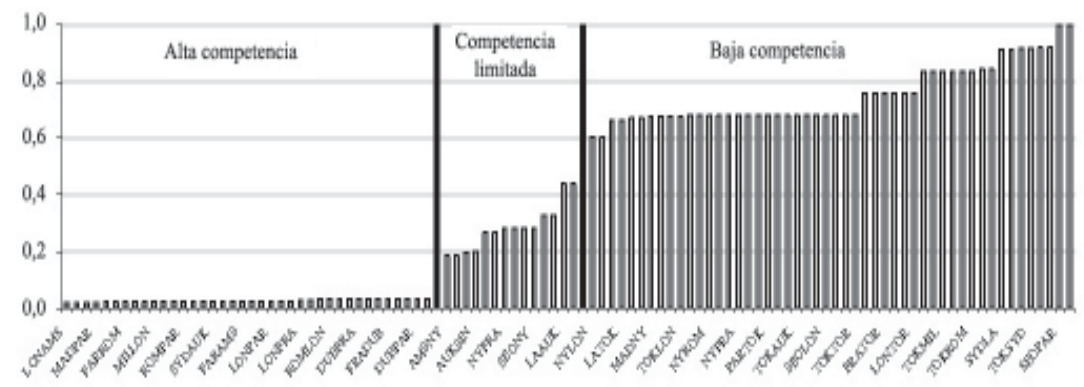

Fuente: Göneç y Nicoletti (2001), reproducida con la debida autorización.

FIGURA No 4: $\quad$ ESTRUCTURA DE MERCADO DE RUTAS ESPECÍFICAS

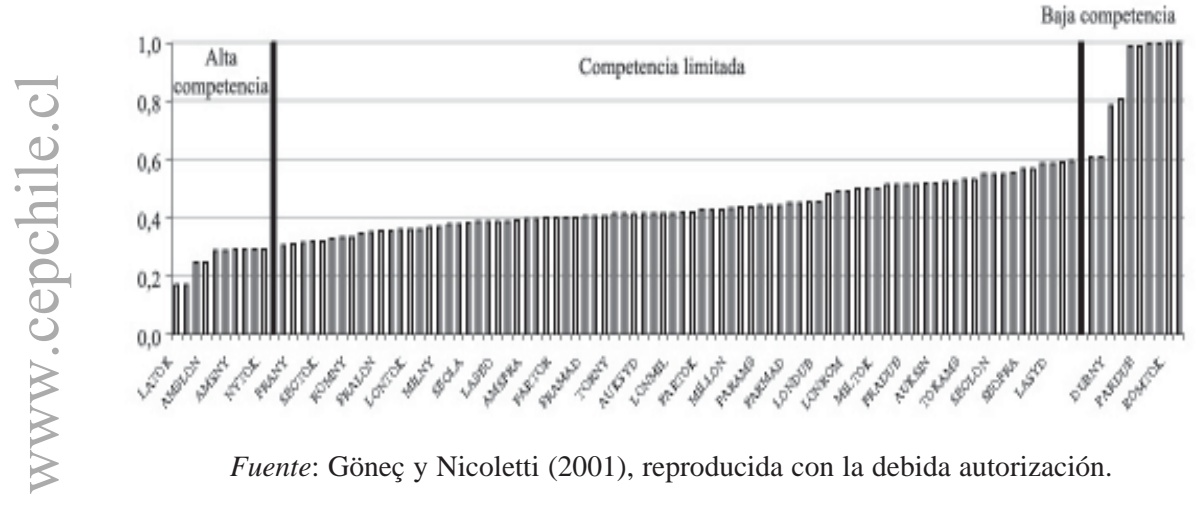


FIGURA N ${ }^{\circ}$ 5: $\quad$ CERCANÍA A LA FRONTERA EFICIENTE DE PRODUCCIÓN EN FUNCIÓN DE LA ESTRICTEZ DEL MARCO REGULATORIO Y DE COMPETENCIA

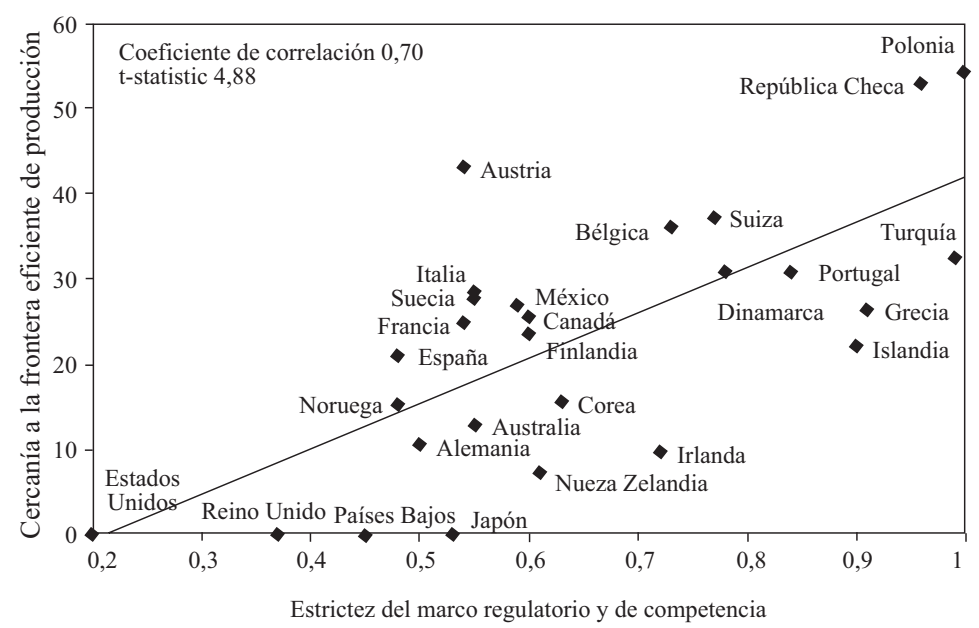

Fuente: Göneç y Nicoletti (2001), reproducida con la debida autorización.

\begin{abstract}
FIGURA N ${ }^{\circ}$ 6: $\quad$ PORCENTAJE PROMEDIO DE ASIENTOS VACÍOS DE LÍNEAS DOMÉSTICAS EN FUNCIÓN DE LA ESTRICTEZ DEL MARCO REGULATORIO Y DE COMPETENCIA
\end{abstract}

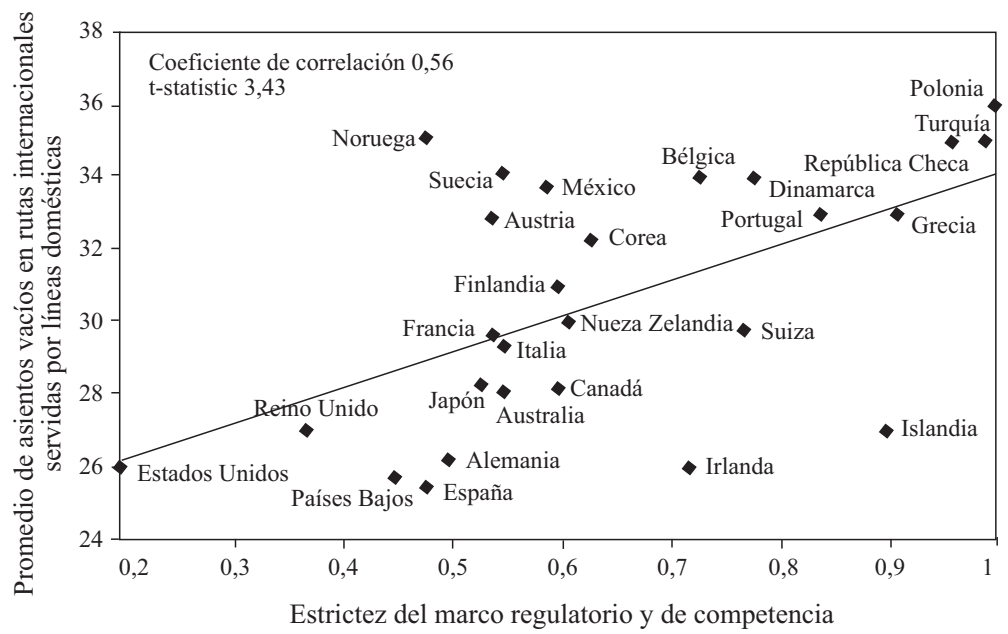

Fuente: Göneç y Nicoletti (2001), reproducida con la debida autorización. 


\section{El modelo}

El modelo que se describe a continuación permite analizar en forma simplificada el efecto de cambios en las libertades y de cambios en el número de frecuencias otorgadas en el marco de un acuerdo aéreo bilateral.

Considero un modelo con demanda lineal única por viajes entre dos puntos A y B, correspondientes a dos países, con demanda inversa $p=a-$ $Q_{d}-Q_{f}, a>0$, donde $p$ es el precio (supuesto único) de los pasajes, y $Q_{d}$, $Q_{f}$ es el número total de pasajeros transportados por las firmas domésticas y extranjeras respectivamente ${ }^{26}$. Suponemos que las aerolíneas domésticas y extranjeras tienen costos marginales constantes e iguales $c$. El supuesto de una demanda lineal sirve para simplificar el análisis. Una forma funcional más general habría ofrecido resultados similares en términos de cambios diferenciales (ya que el análisis de estática comparativa se realiza mediante una linealización en una vecindad del equilibrio original). El inconveniente de una modelación no lineal es que los cambios examinados en este trabajo son discretos: se cambia una libertad por otra o se agrega una frecuencia a las $k$ (con $k$ pequeño) que se permiten actualmente, por lo que un análisis diferencial es inapropiado.

Suponemos que existen $n_{d}$ firmas domésticas y $n_{f}$ firmas extranjeras y que la cantidad de pasajeros transportados entre los dos puntos por la j-ésima firma doméstica y por la j-ésima firma extranjera es $q_{j d}$ y $q_{j f}$ respectivamente, con $\sum_{j} q_{j d}=Q_{d}, \Sigma_{j} q_{j f}=Q_{f}^{27}$. La función de utilidad de la firma i-ésima en $l=d$, $f$ es:

$\pi_{i}=\left(a-\sum_{j=1}^{n_{d}} q_{d j}-\sum_{j=1}^{n_{f}} q_{j f}-c\right) q_{i l}, \quad l=d, f$.

Las condiciones de primer orden para una firma doméstica $i=1, \ldots, n_{d}$ Son:

$\left(a-c-Q_{d}-Q_{f}-q_{d i}\right)-q_{d i}\left(\sum_{j \neq i}^{n_{d}} \frac{\partial q_{d j}}{\partial q_{d i}}+\sum_{j=i}^{n_{f}} \frac{\partial q_{f j}}{\partial q_{d i}}\right)=0$

\footnotetext{
${ }^{26}$ Alternativamente se pueden considerar dos mercados, uno para cada país, con demandas idénticas en cada uno. El modelo supone la perfecta sustitutabilidad en la demanda por aerolíneas, con el objeto de simplificar el análisis.

${ }^{27} \mathrm{El}$ análisis excluye la posibilidad de entrada. Ésta es una formulación natural cuando las barreras a la entrada son regulatorias, como en el caso aéreo.
} 
donde las derivadas parciales $\partial q_{l j} / \partial q_{d i}, l=d$, $f$ denotan la conjetura que tiene la aerolínea i-ésima sobre la reacción de la firma j-ésima a un aumento marginal en la oferta de la aerolínea $i$. El equilibrio que resulta se denomina de variaciones conjeturales. Este concepto es distinto del de un equilibrio de Nash, que supone que las empresas conjeturan que los rivales no reaccionan ante la estrategia de la empresa, lo que resulta en el equilibrio de Cournot en este juego. El equilibrio en variaciones conjeturales tiene el inconveniente de que las conjeturas son erróneas en el equilibrio a menos que sean las conjeturas de Nash, es decir aquellas que suponen que los demás participantes no reaccionan a las acciones de la firma bajo consideración. Pero tiene una ventaja: permite analizar distintos tipos de competencia entre las empresas, ya que éstas se pueden analizar como distintos tipos de conjeturas. De esta forma, al variar el parámetro que describe las conjeturas se puede recorrer todo el arco de la competencia desde la competencia de precios hasta la colusión ${ }^{28}$. En consecuencia, se supondrá que el término $\partial d q_{l j} / \partial d q_{s i}$ puede ser distinto de cero.

Presumamos que cada empresa supone que las demás reaccionan en la misma forma y que el efecto es constante para todas las firmas: $v \equiv \partial q_{l j} /$ $\partial q_{s i} ; \quad l, s=d, f ; j=1 \ldots n_{d}, n_{f}$, con $(l j) \neq(s i)^{29}$. La modelación de conjeturas de esta forma permite abarcar distintos tipos de competencia:

1. $v=0$ implica competencia de Cournot.

2. $v=1$ es colusión. Bertrand).

3. $v=-1 /\left(n_{d}+n_{f}-1\right)$ corresponde a un equilibrio competitivo (o de

Valores intermedios corresponden a grados intermedios de competencia. Un aumento en el parámetro $v$ implica un equilibrio menos competitivo. Se considera una solución simétrica a las condiciones de primer orden del juego entre las empresas, con $q \equiv q_{d i}=q_{d j}=q_{f l}$, ya que las empresas del otro país son tratadas en forma simétrica por la regulación (vía reciprocidad o exclusión, en cuyo caso esas variables no aparecen). Definiendo la constante $\mu \equiv\left(n_{d}+n_{f}+1\right)+v\left(n_{d}+n_{f}-1\right)$ para simplificar las expresiones, $\mathrm{y}$ denominando por $\mu$ a las utilidades de la empresa típica, se tiene:

$$
q=\frac{a-c}{\mu}
$$

\footnotetext{
${ }^{28}$ Ver Dixit (1987).

${ }^{29}$ Las condiciones de segundo orden se cumplen con este supuesto.
} 


$$
\begin{aligned}
& \mathrm{Q}=\frac{\left(n_{d}+n_{f}\right)(a-c)}{\mu} \\
& p=\frac{a\left(1+\left(v\left(n_{d}+n_{f}-1\right)\right)+c\left(n_{d}+n_{f}\right)\right.}{\mu} \\
& p-c=\frac{(a-c)\left(1+\left(v\left(n_{d}+n_{f}-1\right)\right)\right.}{\mu} \\
& \pi=\frac{(a-c)^{2}\left(1+v\left(n_{d}+n_{f}-1\right)\right)}{\mu^{2}}
\end{aligned}
$$

\subsection{Bienestar social}

Usando las expresiones anteriores es posible calcular el bienestar social asociado a distintos tipos de políticas de la autoridad aérea. El bienestar social en equilibrio parcial tiene tres componentes:

- $\quad$ El excedente de los consumidores, que corresponde a lo máximo que hubieran estado dispuestos a pagar los usuarios por los pasajes, en comparación con el valor efectivamente pagado. En la Figura $\mathrm{N}^{\circ} 7$ corresponde al área entre la curva de demanda y el precio de mercado, es decir $C S=(a-p) q / 2$. En el bienestar nacional sólo se debe considerar la fracción de la demanda que corresponde a los consumidores nacionales.

- $\quad$ Las utilidades de las firmas domésticas, representadas por el rectángulo $\Pi_{d}^{30}$.

- $\quad$ Los ingresos del gobierno ${ }^{31}$. En este caso, los ingresos del gobierno no existen, a diferencia del caso de la política comercial, que genera ingresos por aranceles.

Un problema importante es la ponderación que se les debe dar a los distintos componentes del bienestar social. Por razones distributivas, se podría pensar que se debería dar más importancia al excedente del consumidor, como lo hace la regulación por empresa eficiente. Sin embargo, normalmente los intereses de las empresas están concentrados, por lo que tienen

${ }^{30}$ Las utilidades de las firmas extranjeras instaladas en el país forman parte del bienestar del país extranjero.

${ }^{31}$ Se incorporan los ingresos del gobierno, pues éste los puede usar para reducir otros impuestos o para proveer servicios valorados por los ciudadanos. 
FIGURA N ${ }^{\circ}$ 7: $\quad$ BIENESTAR SOCIAL

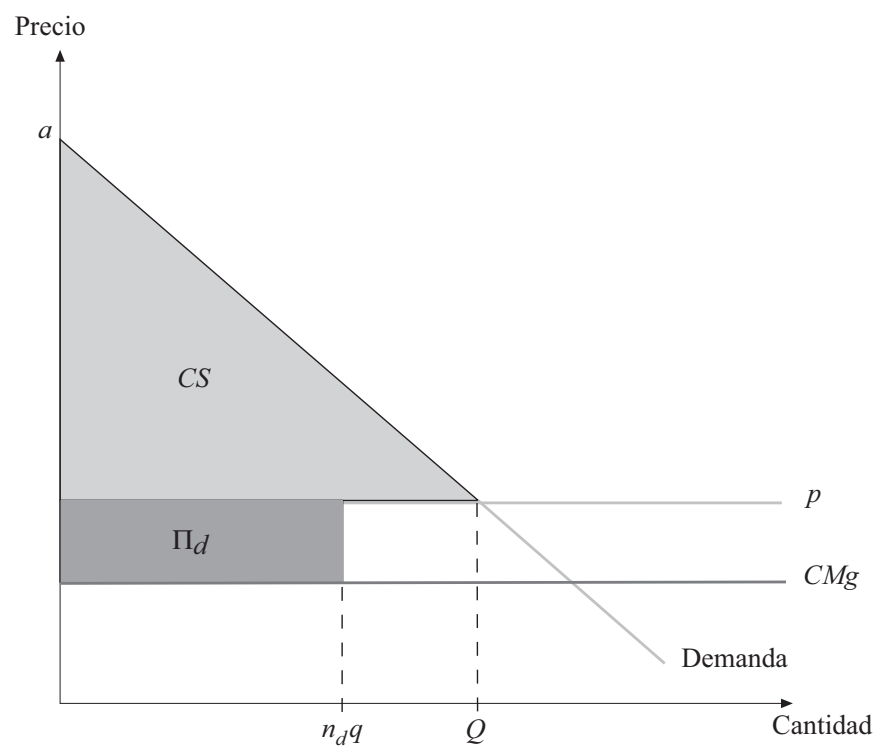

más capacidad de presión política en favor de sus intereses, lo que tendería a darles mayor peso en la función objetivo del regulador ${ }^{32}$. En la primera parte del análisis introduciremos un ponderador de manera que \$ 1 de excedente de los consumidores equivaldrá a $\$ \rho$ de utilidades de las firmas. Además se debe incorporar al análisis el hecho que no todos los que viajan en una ruta son nacionales del país, y por lo tanto debería excluirse su excedente de consumidor de los cálculos.

Para facilitar el análisis se subsumen estos dos aspectos en un solo parámetro $\alpha>0$ : tanto la ponderación de los componentes del bienestar como el hecho que sólo una fracción de los usuarios pertenece al país. Así, es posible escribir el bienestar social como $W=n_{d} \pi+\alpha$ CS. Si el regulador les da excesiva importancia a las utilidades de las firmas, $\alpha$ es pequeño, lo que también ocurre si los consumidores domésticos son una pequeña fracción de todos los usuarios de las frecuencias en la ruta. Entonces es posible determinar el excedente de los consumidores y el de los productores como:

$$
C S=\frac{\left(n_{d}+n_{f}\right)^{2}(a-c)^{2}}{2 \mu^{2}}
$$

32 Para más detalles de este tipo de análisis de economía política, que escapa al campo de este trabajo, ver Helpman (1997). 
$W=\frac{(a-c)^{2}\left[2 n_{d}+2 v n_{d}^{2}+2 v n_{d} n_{f}-2 v n_{d}+\alpha n_{d}^{2}+2 \alpha n_{d} n_{f}+\alpha n_{f}^{2}\right]}{2 \mu^{2}}$

El paso siguiente corresponde a utilizar las expresiones anteriores para la evaluación de políticas aerocomerciales en distintos escenarios de competencia.

\section{Comparación de escenarios}

Como se ha mencionado antes, a diferencia del análisis usual en política comercial estratégica, la política aeronáutica no se basa en tarifas, sino en restricciones cuantitativas o cualitativas. Las limitaciones de capacidad o de frecuencia en una ruta, dentro de una misma libertad, corresponden a las restricciones cuantitativas. En el lenguaje del comercio internacional, son el equivalente a una cuota a las importaciones (o a las exportaciones).

Esto no sería una complicación importante, porque el análisis de cuotas es relativamente estándar en teoría del comercio internacional, incluso en condiciones de competencia oligopólica. La dificultad estriba en que el análisis estándar es para un bien homogéneo, y aquí se trata de un bien diferenciado, ya que las líneas aéreas ofrecen tarifas distintas para el mismo vuelo, imponiendo condiciones que intentan discriminar entre los usuarios. Por lo tanto, una restricción de frecuencia tiene un efecto más complejo que en el caso de un bien homogéneo. Una forma de abordar el problema es suponer que la posibilidad de diferenciar las tarifas tiene un efecto similar al de una regla de racionamiento eficiente bajo una restricción de capacidad, ya que estas reglas permiten que primero tengan acceso al bien o servicio los consumidores que tienen mayor excedente del consumo del bien o servicio, tal como lo hace la diferenciación de tarifas mediante restricciones. Además, en principio, una buena aplicación de las técnicas de yield management debería asegurar que la capacidad disponible sea aprovechada en forma óptima ${ }^{33}$.

Por su parte, las restricciones cualitativas se pueden asimilar al establecimiento de éstandares máximos de calidad para los servicios (según esa interpretación, una libertad más "liberal” corresponde a un servicio de mejor

${ }^{33} \mathrm{El}$ análisis de bienestar con bienes diferenciados y cuotas es complejo. Berry, Levinsohn y Pakes (1999) han estudiado el efecto de bienestar de las restricciones voluntarias a las exportaciones de automóviles procedentes de Japón hacia EE.UU., y examinan el efecto de estas restricciones cuantitativas en mercados con productos diferenciados. Sin embargo, la complejidad del análisis y los requerimientos de información están fuera del alcance de este trabajo. 
calidad desde el punto de vista de los usuarios efectivos o potenciales en la ruta). A continuación se analizan los efectos de modificar las restricciones cuantitativas y cualitativas y lo que se puede esperar en términos de bienestar social.

\subsection{Otorgamiento de una libertad más generosa}

Una libertad mayor equivale a aumentar el valor de los vuelos para los usuarios, en el sentido de darles más flexibilidad. Por ejemplo, una escala intermedia en la que se pueden tomar y bajar pasajeros - a diferencia de una en que no se puede hacer- claramente representa un aumento en el bienestar para los usuarios que ahora disponen de más alternativas. Dado que esto debería aumentar la demanda por usar la ruta, modelamos este cambio como un desplazamiento de la curva de demanda hacia afuera desde $D$ a $D^{\prime}$, como se observa en el recuadro izquierdo de la Figura $\mathrm{N}^{\circ} 8$. El resultado es un aumento en la cantidad y en los precios, a menos que el mercado sea perfectamente competitivo, caso en el que los precios se mantienen a costo marginal, o a costo medio si hay costos fijos.

El análisis de los efectos de bienestar en este caso se basa en la expresión (9) para el bienestar, considerando el hecho que se comparan curvas desplazadas. Si los parámetros $A$ y $a$ denotan la intersección de la demanda con el eje vertical en los casos con y sin la libertad adicional, definimos $\Delta=(A-c)^{2}-(a-c)^{2}$, una constante que será útil en el desarrollo posterior. Nos interesa comparar el cambio en el bienestar social producto
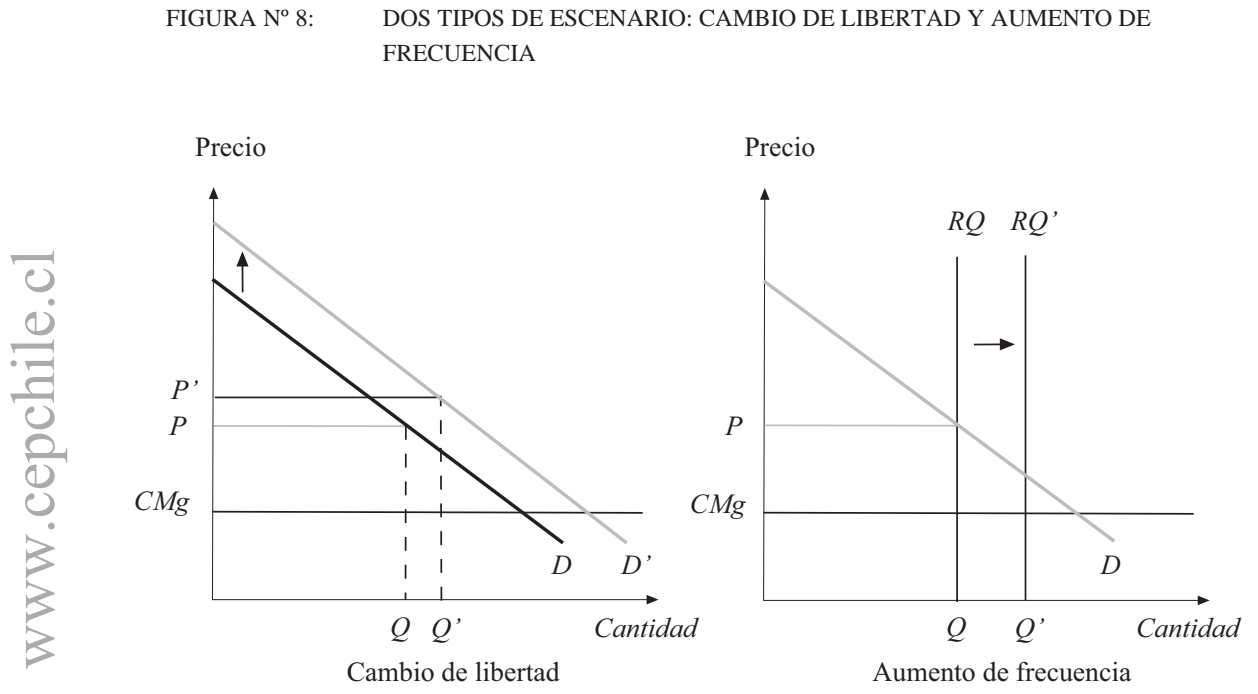
del desplazamiento de la demanda asociado al otorgamiento de una libertad mayor en la ruta (es decir de $a$ a $A$ ), en el caso de distintas estructuras de mercado en ambos países. Los escenarios que siguen corresponden a distintos tipos de situaciones de competencia luego de permitirse una libertad más generosa en una ruta ${ }^{34}$ :

\subsubsection{Monopolio extranjero: $n_{d}=0, n_{f}=1$}

En este caso hay una sola firma operando en la ruta y ésta es extranjera. El cambio en el bienestar social es $\Delta W=\alpha \Delta / 8$. En este caso, hay una transferencia de rentas desde el país doméstico al extranjero, lo que se traduce en que el país doméstico sólo obtiene el bienestar asociado al cambio en el excedente de sus consumidores debido a la nueva libertad.

\subsubsection{Monopolio nacional: $n_{d}=1, n_{f}=0$}

En este caso, la única firma que opera en el mercado es doméstica. El cambio en el bienestar social es $\Delta W=(2+\alpha) \Delta / 8$, es decir, mucho mayor que en el caso anterior, ya que las utilidades monopólicas las recibe la empresa doméstica y no hay transferencia de rentas al extranjero. Se debe notar, sin embargo, que las rentas se concentran en la empresa y que el bienestar de los usuarios no mejora respecto al caso anterior.

\subsubsection{Duopolio binacional: $n_{d}=n_{f}=1$}

Se trata de una situación en que existen dos firmas operando la ruta, cada una perteneciente a uno de los dos países. El cambio en el bienestar social en este caso es:

$$
\Delta W=\frac{\Delta(1+v+2 \alpha)}{(3+v)^{2}}
$$

que puede alcanzar distintos valores, dependiendo del tipo de competencia entre las firmas, lo que está parametrizado por $v$. Los casos interesantes son:

${ }^{34}$ Se debe recordar que si no se permiten vuelos de una determinada libertad entre dos destinos, el bienestar asociado es cero, lo que es la peor situación posible. Esto no significa que el bienestar social efectivo sea cero, sino que, en relación con lo que se podría conseguir si se otorgara esa libertad, el cambio en el bienestar es cero. 
Cartel duopólico $(v=1)$. El cambio en el excedente social es $\Delta W=(\alpha+1) \Delta / 8$.

Competencia de Cournot $(v=0)$. El cambio en el excedente social es $\Delta W=$ $(2 \alpha+1) \Delta / 9$.

Competencia de Bertrand $(v=-1)$. El cambio en el excedente social es $\Delta W=$ $\alpha \Delta / 2$.

Es importante observar que el bienestar con un cartel es inferior al que se obtendría con un monopolio nacional, ya que en el primer caso, las aerolíneas doméstica y extranjera se dividen las rentas que se generan en los dos países.

Se puede mostrar que, a menos que $\alpha$ sea muy pequeño $(\alpha<(1-v) / 4)$, se tiene una relación monotónica positiva entre el grado de competencia entre las firmas y el bienestar social en el caso duopólico con una empresa en cada país. Para verificar este resultado, basta observar que en la expresión (10) la derivada con respecto a $v$ es $\Delta(1-v-4 \alpha) /(3+v)^{3}$, y si se cumple la condición anterior sobre $\alpha$, a medida que $v$ aumenta (el mercado es menos competitivo) cae el bienestar social, siempre y cuando el peso de los consumidores en el bienestar del regulador $(\alpha)$ no sea demasiado peque$\tilde{n} 0^{35}$. Por lo tanto, en el caso de dos firmas, el cambio de libertad es siempre positivo para el país, y el consecuente ordenamiento es: el aumento en el bienestar social asociado a una mayor libertad es más alto con Bertrand que con Cournot, que a su vez es mayor que con un cartel.

\subsubsection{Duopolio extranjero: $n_{d}=0, n_{f}=2$}

En este caso hay un duopolio, pero sólo de firmas extranjeras. El cambio en el bienestar social en este caso es $W=2 \alpha \Delta /(3+v)^{2}$, que depende del grado de competencia entre las firmas. Claramente es menor que en el caso del duopolio binacional, salvo para el caso $v=-1$, que corresponde a Bertrand o competencia perfecta. En este caso, el bienestar social es el mismo que con un duopolio nacional, pues no hay transferencia de renta.

$$
\begin{aligned}
& { }^{35} \text { En el caso general con } n_{d}, n_{f} \text { empresas, la derivada del bienestar es } \\
& \operatorname{sgn}\left(\frac{\partial W}{\partial v}\right)=-\operatorname{sgn}\left(-n_{d}^{2}-n_{d} n_{f}+n_{d}+n_{d}^{2} v+n_{d} v n_{f}-n_{d} v+\alpha n_{d}^{2}+2 \alpha n_{d} n_{f}+\alpha n_{f}^{2}\right) .
\end{aligned}
$$

Este signo puede ser positivo en un rango de $n_{d}$ (dado $n_{f}$ ), por lo que el bienestar puede aumentar a medida que la competencia decrece, debido a la extracción de rentas del extranjero. A esto contribuye la importancia que tenga el bienestar de los consumidores en la función objetivo del regulador. Si es el factor más relevante, mayor competencia es siempre deseable. 
Con un cartel, el bienestar social es el mismo que si hubiera una sola firma (extranjera) operando en el mercado.

\subsubsection{Duopolio nacional $n_{d}=2, n_{f}=0$}

Si el duopolio consiste sólo de firmas nacionales, el cambio en el bienestar social es $\Delta W=2 \Delta(1+v+\alpha) /(3+v)^{2}$. Si las utilidades de las empresas se ponderan igual o menos que el excedente de los consumidores, mayor competencia es mejor. A medida que el regulador les da más importancia a las utilidades de las empresas, el bienestar máximo tiende a alcanzarse con menos competencia. Derivando el bienestar respecto a $v$, $\operatorname{sgn}(d W /$ $d v)=\operatorname{sgn}(1-2 \alpha-v)$. Por lo tanto si $\alpha=1 / 2$, el máximo bienestar se alcanza con Cournot.

Para resumir, un aumento en la libertad siempre aumenta el bienestar si se mantiene la estructura de mercado, pero el aumento es mayor cuando las empresas de ambos países reciben este beneficio (es decir, bajo reciprocidad). Por otra parte, a medida que se les da menos importancia a los consumidores, cada vez es más ventajosa una situación en que la asimetría beneficia al país bajo análisis, es decir, cuando no se extienden los beneficios de la mayor libertad al otro país. Sin embargo, a medida que aumenta la competencia en los mercados, la nacionalidad de las aerolíneas se hace menos importante, pues casi todos los beneficios terminan en manos de los consumidores. En tal caso, una política de reciprocidad es irrelevante y la política óptima consiste en otorgar mayores libertades, aun sin reciprocidad.

\section{2 . Aumento de frecuencias dentro de una misma libertad}

Para analizar estos escenarios es útil un supuesto fuerte: se supondrá que las aerolíneas manejan sus vuelos eficientemente, adaptando sus tarifas de manera que los aviones sean utilizados en forma eficiente, dada la regulación y las condiciones de mercado. En tal caso, un aumento de frecuencias es equivalente a relajar la restricción cuantitativa, como se observa en el recuadro derecho de la Figura $\mathrm{N}^{\circ}$ 8. En tal caso, los consumidores siempre se benefician con el mayor número de frecuencias, y las empresas están mejor o peor dependiendo de si la restricción de frecuencias es más estricta que en un equilibrio monopólico o no.

El razonamiento anterior implica que la limitación de frecuencias ayuda a cartelizar la industria ${ }^{36}$. En consecuencia deberíamos observar colabo-

\footnotetext{
${ }^{36}$ Esto ha sido señalado por Harris (1985), para el caso de las restricciones voluntarias a las importaciones.
} 
ración entre las empresas —especialmente en el caso de duopolios binacionales-, las que sólo pedirán una ampliación de las frecuencias si las frecuencias están bajo el nivel monopólico, como se muestra en la Figura № 9. Esto sólo ocurriría si hay un cambio en las condiciones de mercado, como, por ejemplo, un aumento en la demanda por la ruta. Generalizando esta idea, sólo habría presiones sobre el regulador para ampliar las frecuencias si existiesen participantes que, dado el grado de competencia existente, aumentasen su utilidad marginal al aumentar las frecuencias de vuelos.

Este análisis ayuda a estimar los beneficios que se obtendrían de una ampliación de frecuencias. Primero, los beneficios los recibirían los consumidores, a menos que la ampliación haya sido solicitada por las empresas. La explicación es que si las empresas se opusiesen a la ampliación de frecuencias, esto se debería a que utilizar las frecuencias adicionales reduciría sus rentas, y, si no las usan, esto permitiría que otra empresa entre al mercado, aprovechando las frecuencias no utilizadas, lo que aumentaría la competencia, con la consiguiente reducción de rentas para las firmas existentes. Segundo, los argumentos anteriores permiten suponer que la limitación de frecuencias (si se estudia un duopolio binacional o un monopolio de los vuelos) reproduce la frecuencia deseada por un monopolio. En tal caso,
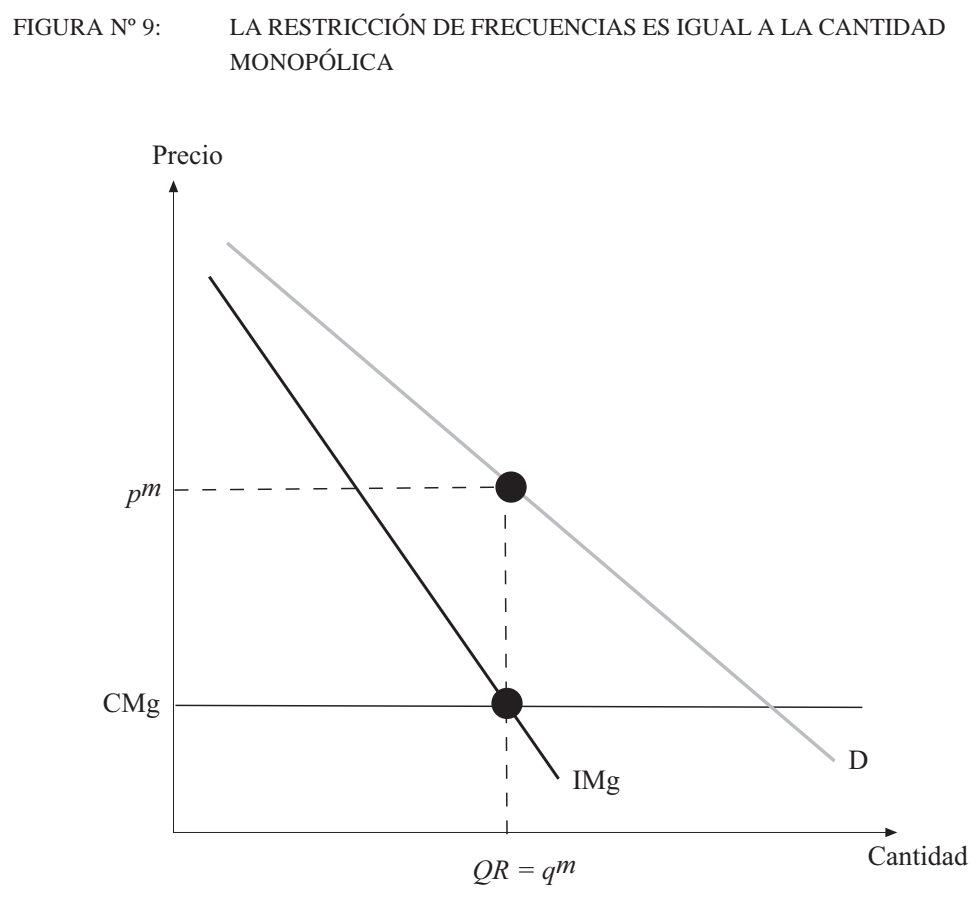
basta conocer la demanda (y por lo tanto su elasticidad $\varepsilon$ ) para determinar el costo unitario $c$ usando el margen de Lerner de un monopolio:

$$
\frac{p-c}{p}=\frac{1}{\varepsilon}
$$

donde $p$ es el ingreso por vuelo, $c$ son los costos marginales asociados y $\varepsilon$ es la elasticidad de la demanda. Es decir, es posible derivar el bienestar si se conoce el ingreso por cada frecuencia en una ruta.

El análisis de bienestar en este caso es más sencillo que en el anterior, ya que dada la restricción de frecuencia y el supuesto de yield management eficiente, el precio queda determinado por la intersección de la demanda con la restricción cuantitativa. A su vez, esto determina el excedente de los consumidores. Las utilidades totales, que equivalen a $\Pi=(P(Q R)-c) Q R$ (donde $Q R$ es la restricción cuantitativa o de frecuencia), se dividen de acuerdo al número de firmas de cada país — suponiendo la misma eficiencia en las empresas nacionales y extranjeras-, y no es necesario hacer un análisis de distintas formas de competencia, ya que en un equilibrio simétrico basta conocer el número de firmas en cada mercado.

\subsection{Simulación del efecto de una liberalización de frecuencia}

Debido a que un estudio de los efectos de un cambio en las libertades requiere conocer el cambio en la demanda que se produce, y no hay elementos (datos, estudios de demanda, etc.) para analizar ese caso, examinaremos en forma muy sucinta el caso de un aumento en las frecuencias, que es relativamente más fácil de estudiar con la metodología descrita en la sección anterior.

Incluso en este caso, debido a la falta de información sobre la elasticidad de la demanda para las rutas que salen o llegan a Chile, y a los costos asociados, se deben hacer algunas hipótesis heroicas y una multitud de supuestos simplificadores para poder estimar los cambios en bienestar. La esperanza es que los resultados al menos permitan determinar en forma aproximada los impactos del aumento de frecuencia. Interesa al menos determinar el orden de magnitud del cambio en el bienestar social anual al aumentarse en una frecuencia semanal los viajes entre destinos no cubiertos por acuerdos de cielos abiertos.

Para este análisis, supondremos que las empresas importantes en el mercado en cuestión presionan para aumentar las frecuencias hasta el límite colusivo, es decir, aquel que satisface la ecuación (11). Esto permite estimar 
los costos marginales a partir de los valores del precio y la elasticidad de la demanda. A partir de este cálculo es posible estimar el margen unitario (por pasajero) como la diferencia entre el valor del pasaje y los costos determinados a partir de (11) y luego el margen generado por una frecuencia adicional al multiplicar la cifra anterior por la tasa de ocupación de los vuelos en la ruta.

Para estudiar el excedente de los consumidores supondremos que la demanda por vuelos entre un par origen-destino tiene elasticidad constante, es decir, la demanda se escribe $q=\alpha p^{-\varepsilon}$, con elasticidad $\varepsilon$. La Figura $\mathrm{N}^{\circ} 10$ muestra la forma de la demanda para distintas elasticidades. El excedente bruto de un consumidor se obtiene como un múltiplo del precio del pasaje, a partir de la expresión

$$
E C B=\int_{0}^{q} \frac{v^{-1 / \varepsilon}}{\alpha} d v
$$

donde $q$ es la demanda observada.

FIGURA N ${ }^{\circ}$ 10: DEMANDA INVERSA CON ELASTICIDAD CONSTANTE
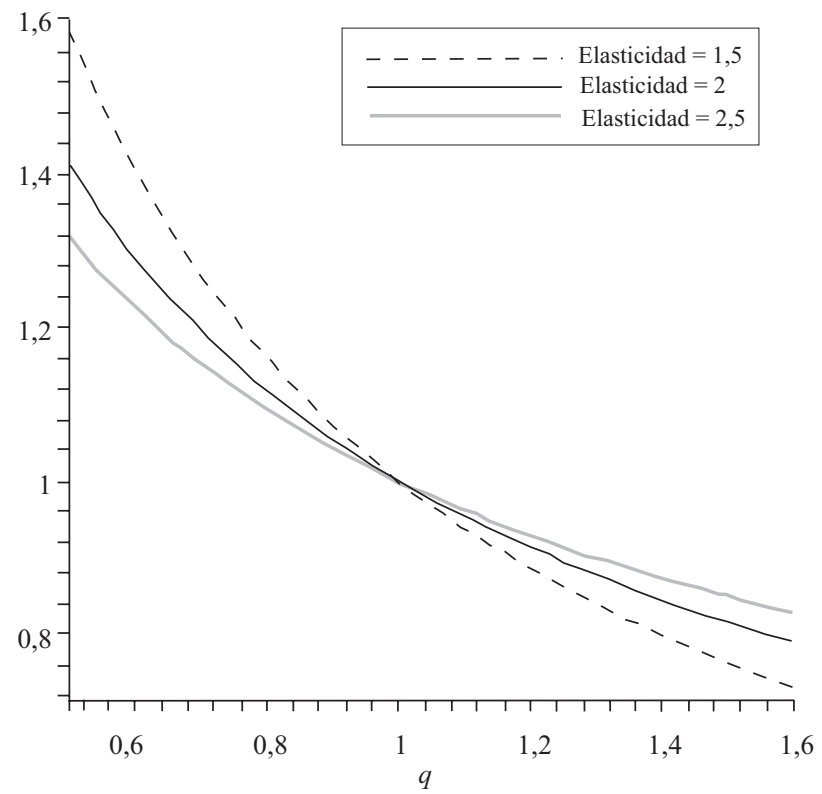
FIGURA N ${ }^{\circ}$ 11: COMPONENTES DEL BIENESTAR CON PRECIO MÁXIMO

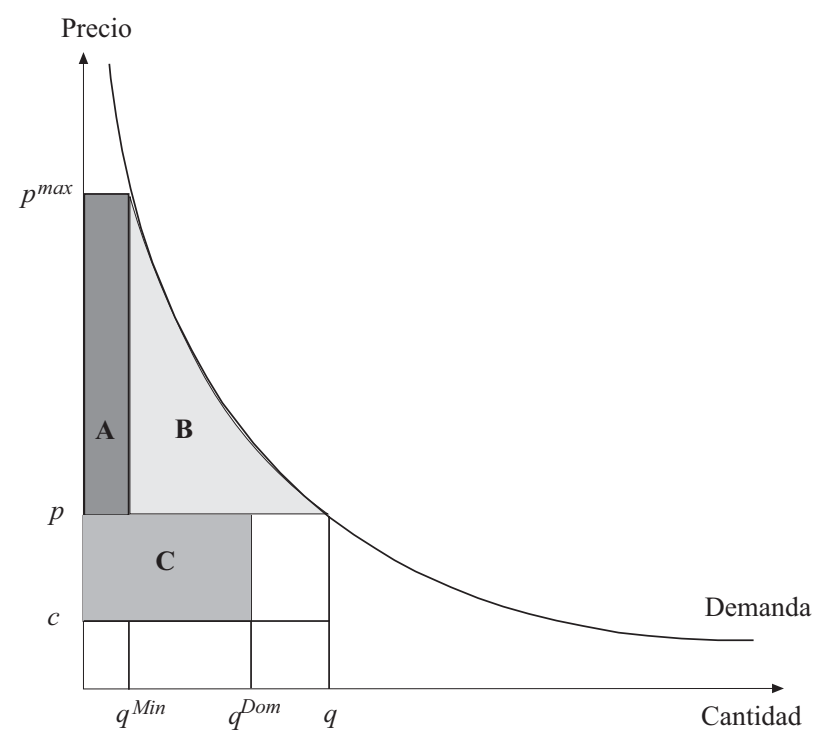

Para evitar que las estimaciones se vean distorsionadas por las características de la función de demanda, que puede darle demasiada ponderación a consumo a precios muy elevados, imponemos un precio máximo ${ }^{37}$. Por lo tanto no consideramos el excedente del consumidor por encima de este valor. En tal caso, la Figura $\mathrm{N}^{0} 11$ describe los distintos componentes del excedente social. A + B corresponde al excedente de los consumidores y C es el excedente que reciben las aerolíneas nacionales (el resto va a las líneas extranjeras en la ruta). Nótese que $q^{\text {Min }}$ corresponde al consumo asociado al precio máximo $p^{M a x}$, y que $q^{D o m}$ son las ventas de las firmas domésticas.

\subsubsection{Estimaciones del valor social de una frecuencia adicional}

Las siguientes estimaciones se hicieron considerando países con los cuales no hay acuerdos de cielos abiertos y, por lo tanto, las frecuencias otorgadas deberían ser menores que las que ocurrirían bajo cielos abiertos,

${ }^{37}$ Una manera de interpretar el precio máximo es suponer que existen alternativas a los vuelos en líneas comerciales, y que por encima de un cierto valor es posible y preferido arrendar un jet privado para el viaje, lo que pone un techo al precio máximo por el que se consume el servicio "vuelo en aerolínea comercial”. 
ya que requieren el acuerdo de ambos países. Utilizaremos el supuesto que en tal caso las frecuencias otorgadas responden a los intereses de las firmas que operan entre ambos países.

Las estimaciones de excedentes del consumidor y costos sociales se construyeron cotizando los valores de un pasaje turista de mínimo precio con una estadía de una semana en el destino. Se eligieron los destinos de Lima, Madrid y Ciudad de México por ser destinos importantes con los que no hay acuerdos de cielos abiertos y porque las rutas en cuestión son operadas casi exclusivamente por dos empresas. La participación de las dos mayores empresas es de 99\% en la ruta Santiago-C. de México, 85\% en Santiago-Madrid y 99\% en Santiago-Lima, si consideramos que Lan Perú se maneja estratégicamente en conjunto con Lan (usando cifras de 2005). Por lo tanto, supondré que es válido el supuesto que las frecuencias solicitadas corresponden a lo que desearía el duopolio que controla la ruta. El Cuadro $\mathrm{N}^{\circ} 2$ muestra los valores de los pasajes en esas rutas ${ }^{38}$.

Para calcular el costo unitario se usa la expresión (11). Los cálculos se realizan de acuerdo al modelo que aparece en el Apéndice. Se calcula el cambio en el bienestar como el cambio en los distintos componentes del bienestar al autorizarse una frecuencia semanal adicional, suponiendo 100 pasajeros por viaje y suponiendo que dado que los pasajeros que vuelan por la firma doméstica son los nacionales, se multiplican los valores obtenidos por la proporción observada de pasajeros domésticos en la ruta. Las cifras obtenidas son anuales.

CUADRO N ${ }^{\circ}$ 2: $\quad$ VALORES DE PASAJES TURISTA, DESTINOS PRINCIPALES

\begin{tabular}{lrrr}
\hline & Lima & C. de México & Madrid \\
\hline & & & \\
Pasajeros anuales 2005 & 259.791 & 152.783 & 289.164 \\
Valor pasaje US\$ & 417 & 904 & 2.979 \\
Porcentaje línea nacional & $70 \%$ & $77 \%$ & $45 \%$ \\
Tasas y/o impuestos & 43 & 977 & 3.189 \\
Valor total & 460 & & \\
\hline
\end{tabular}

Nota: Cuadro corresponde a información disponible en la página web de Lan Chile.

${ }^{38}$ Cotizado el 23 de junio de 2006 para viajar el 15 de julio de 2006 con regreso el 23 de junio de 2006 en el caso Santiago Madrid. En los casos de Lima y Ciudad de México, los valores son del 28 de octubre para un pasaje con estadía de una semana entre el 18 y 25 de noviembre. Los valores cambian rápidamente y, al cabo de media hora, algunas tarifas no estaban disponibles. 
El cambio en el bienestar social asociado a una frecuencia adicional es significativo, como se muestra en el Cuadro $\mathrm{N}^{\circ} 3$. La mayor parte de los beneficios la reciben los usuarios (aunque una fracción entre el 30 y 40\% de ellos la recibe la línea aérea en la forma de mayores utilidades). La magnitud del efecto depende de la elasticidad de la demanda. El beneficio social de una frecuencia adicional se encuentra entre los 2 y los 10 millones de dólares anuales, dependiendo de la elasticidad de la demanda.

CUADRO No 3 : EFECTO DE AUMENTAR UNA FRECUENCIA SEMANAL

\begin{tabular}{|c|c|c|c|}
\hline & & Elasticidad & \\
\hline Madrid & 1.5 & $\mathrm{e}=2.0$ & $\mathrm{e}=2.5$ \\
\hline Qmin & 16.622 & 6.415 & 2.475 \\
\hline Costo unitario & 993 & 1.490 & 1.787 \\
\hline A & 128.700 .000 & 49.680 .000 & 19.180.000 \\
\hline B & 722.000 .000 & 667.000 .000 & 615.700 .000 \\
\hline $\mathrm{C}$ & 261.300 .000 & 185.900 .000 & 156.770 .000 \\
\hline W & 1.112 .000 .000 & 912.780 .000 & 791.600 .000 \\
\hline$\Delta \mathrm{B}$ & 7.006 .000 & 7.010 .000 & 7.020 .000 \\
\hline$\Delta \mathrm{C}$ & 4.690 .000 & 3.524 .000 & 2.810 .000 \\
\hline$\Delta \mathrm{W}$ & 11.700 .000 & 10.054 .000 & 9.820 .000 \\
\hline \multicolumn{4}{|l|}{ Lima } \\
\hline Qmin & 2.212 & 451 & 92 \\
\hline Costo unitario & 139 & 209 & 250 \\
\hline A & 14.770 .000 & 3.017 .000 & 616.000 \\
\hline B & 180.260 .000 & 144.700 .000 & 125.000 .000 \\
\hline $\mathrm{C}$ & 50.300 .000 & 37.700 .000 & 30.200 .000 \\
\hline W & 245.000 .000 & 185.400 .000 & 155.000 .000 \\
\hline$\Delta \mathrm{B}$ & 1.501 .000 & 1.503 .800 & 1.505 .000 \\
\hline$\Delta \mathrm{C}$ & 1.007 .000 & 755.600 & 604.500 \\
\hline$\Delta \mathrm{W}$ & 2.508 .900 & 2.259 .000 & 2.109 .000 \\
\hline
\end{tabular}

C. de México

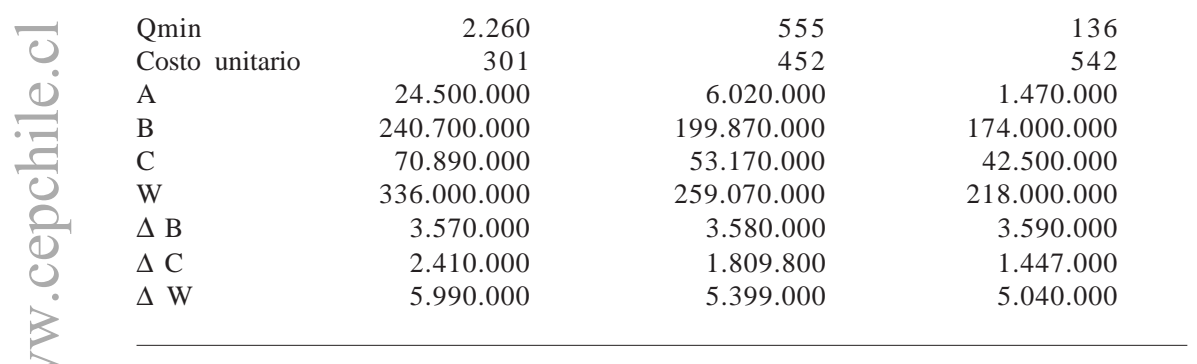

Nota: Cálculos del autor. Beneficios medidos en US\$. 


\section{Extensiones}

Esta sección describe algunas extensiones al modelo simple que lo hacen más realista. La primera consiste en introducir la opción de sustitución entre destinos. Si no se otorga una cierta libertad entre dos destinos (por ejemplo, en Madrid), ésta se puede reemplazar por la misma libertad en un destino alternativo (París). El segundo tema apunta a estudiar el efecto de diferencias de costos y por lo tanto los efectos de la eficiencia sobre el bienestar ${ }^{39}$.

\subsection{Política de reciprocidad y sus costos}

Una política de reciprocidad tiene la ventaja de que si se alcanzara un acuerdo para liberalizar los vuelos entre dos países, los beneficios se repartirían entre ambos países. Sin embargo, esto tiene un costo, pues podría retrasar un acuerdo beneficioso para ambas partes (aun cuando los beneficios no se repartan en forma equitativa). Los modelos teóricos de la sección anterior muestran que una política de cielos abiertos, sin solicitar reciprocidad, puede no causar pérdidas: esto ocurre en todos los casos en que hay suficiente competencia en el mercado aéreo extranjero. En este caso, exigir reciprocidad implicaría retrasar beneficios inmediatos a cambio de nada (ya que con competencia extranjera, las firmas nacionales no obtendrían rentas en ningún caso).

Incluso en condiciones menos extremas se puede observar este efecto, como en el caso en que originalmente dos firmas extranjeras y una firma nacional operan una ruta bajo una determinada libertad, y se desea liberalizar la ruta. Si el país extranjero no está dispuesto a liberalizar, el país doméstico podría ofrecer unilateralmente la libertad adicional sólo a las firmas extranjeras, excluyendo así a la firma doméstica de los beneficios de la nueva libertad. Si existiera suficiente competencia en el país extranjero, los beneficios para los consumidores domésticos excederían la transferencia de rentas, pese a que la firma doméstica esté excluida de la libertad adicional. Aunque la reciprocidad habría sido preferible, las rentas que deje de ganar la firma doméstica serán inferiores a los beneficios adicionales que reciben los viajeros.

Esto lleva a concluir que la decisión de una política de este tipo debe ponderar los beneficios de una liberalización unilateral, contra los mayores beneficios de una apertura recíproca, pero que puede tardar, o no ocurrir.

${ }^{39}$ El Apéndice contiene un análisis de un argumento utilizado para oponerse a la liberalización del cabotaje doméstico: los períodos de punta y fuera de punta. 
El siguiente esquema de análisis da cuenta de los factores a considerar. Sea $W_{u}>0$ el cambio en el bienestar social bajo liberalización unilateral $^{40}$. Sea $W_{b} \geq W_{u}$ el bienestar bajo liberalización bilateral. Supondremos que la liberalización unilateral tiene efecto inmediato, pero que, en cambio, la liberalización bilateral tiene una probabilidad $0<p<1$ de ocurrir cada período. Entonces la condición para estar indiferentes entre la política de apertura unilateral y la política de reciprocidad es:

$$
W_{u}=\sum_{0}^{\infty} \frac{p(1-p)^{j} W_{b}}{(1+r)^{j}}=p W_{b}\left(\frac{1+r}{r+p}\right)
$$

De esta expresión se desprende que la política de reciprocidad se hace más atractiva:

1. Si el bienestar que se obtiene bajo un acuerdo bilateral $W_{b}$ es más alto.

2. Si el bienestar bajo liberalización unilateral $W_{u}$ es más bajo.

3. Si aumenta la probabilidad de una negociación bilateral exitosa $p$.

4. Si cae la tasa de interés $r$, que es el costo de esperar para llegar a un acuerdo.

Este análisis simple no ha considerado un factor importante: el valor de la reputación. Si un país es percibido por los otros países como uno que aceptaría fácilmente condiciones de apertura unilateral, es probable que los otros países hagan un cálculo similar para ver si a ellos les conviene intentar que el otro país acepte la apertura unilateral. Este análisis, sin embargo, escapa al alcance de este trabajo.

\subsection{Rutas alternativas (sustitución)}

El costo de las restricciones a los vuelos entre dos países puede depender de la posibilidad de sustitución entre destinos. Por ejemplo, si se estudia el efecto de restricciones a los vuelos entre Santiago y Madrid, una parte del efecto de la restricción podría verse diluida si los vuelos de Santiago a París no tienen limitaciones a las frecuencias. Para modelar este efecto y estudiar cómo depende de la sustitución y del grado de competencia entre los países, consideraré una parametrización particularmente sencilla: supondré que la demanda por vuelos entre los destinos A y B aumenta con el precio $p_{2}$ de los viajes entre A y C. Entonces se tiene: $p_{1}=a-x+b p_{2}, b>0$.

\footnotetext{
${ }^{40}$ Se supone positivo, porque los viajeros siempre podrían no utilizar la flexibilidad que permite la mayor libertad en la ruta.
} 
La modelación permite considerar en forma reducida el efecto de competencia en el mercado sustituto (a través del precio $p_{2}$ ) para un valor dado de la sustitutabilidad. Dado que considero que las líneas aéreas operan en los dos mercados en forma independiente, el único efecto de la introducción del nuevo destino en las expresiones anteriores para el bienestar social es que se debe reemplazar el parámetro $a$ de la demanda por $a^{\prime} \equiv a+b p_{2}$.

En tal caso, se tiene que un aumento en la competitividad del mercado sustituto, que se refleja en la caída en el precio en ese mercado, es equivalente al desplazamiento hacia adentro de la curva de demanda en el mercado original. Esto se debe a que la introducción de un mercado sustituto hace menos importante el mercado original. Por lo tanto, los precios tienden a bajar mientras más bajo es el precio en el mercado sustituto. El resultado es que los problemas de competencia y de acceso se hacen menos relevantes y el mercado es menos valioso cuando existen rutas sustitutas con menores restricciones de frecuencias o libertades. En tal caso, el costo de una estrategia de reciprocidad es menor ${ }^{41}$.

\section{Conclusiones}

El análisis de este sencillo modelo muestra que:

1. Si una política de reciprocidad conduce a que no se desarrolle un mercado en términos de mayores frecuencias o mayores libertades, el costo social puede ser elevado. Las estimaciones de este trabajo muestran que el costo de los atrasos en expandir el número de frecuencias puede ser de varios millones de dólares al año.

2. La política de reciprocidad (bajo la condición de que el mercado se desarrolle) conduce a mejores resultados que una política de cielos abiertos en la que un monopolio en el extranjero recibe todos los beneficios.

3. Una alternativa deseable es la existencia de competencia en los vuelos al mercado local, lo que lleva al máximo el bienestar.

4. Alternativamente, una política de cielos abiertos es óptima si hay competencia en el país extranjero por volar a nuestro país.

5. La existencia de un mercado sustituto más competitivo reduce el costo de espera de la estrategia de reciprocidad.

6. Los costos y beneficios de una política de reciprocidad dependen de:

a) Costo de esperar un resultado favorable.

\footnotetext{
${ }^{41}$ Aunque también los beneficios de conseguir condiciones recíprocas son me-
} nores. 
b) Beneficios que se reciban.

c) Beneficios que se alcancen si no se obtiene el resultado favorable.

d) La probabilidad de éxito bajo la política de reciprocidad.

7. Las simulaciones para tres destinos sin cielos abiertos muestran que el valor, en términos de bienestar social, de una frecuencia adicional es importante, y corresponde a varios millones de dólares.

Para llegar a conclusiones más definitivas sobre la competencia en el mercado internacional se requiere disponer de información de mejor calidad. Dado que parece imposible conseguir información del yield de las empresas, que podrían alegar que es información estratégica, es necesario pensar en alternativas. Una posibilidad es realizar encuestas a la salida y entrada de las zonas de seguridad del aeropuerto, en las que se pregunte a los viajeros por su destino, el precio que pagaron, el día de regreso, etc. ${ }^{42}$. Este tipo de encuestas, realizadas en forma trimestral, podría generar información imprescindible para conocer el mercado, el grado de competencia en el sector, el valor social de una frecuencia adicional, estudiar la demanda por rutas y otras variables similares. Esto permitiría que las decisiones de política aerocomercial pudieran tomarse con información más sólida que la que existe actualmente ${ }^{43}$.

\section{APÉNDICE}

\section{A. Un argumento contra la liberalización: períodos de punta y fuera de punta}

Chile no permite el cabotaje aéreo de empresas extranjeras (sin reciprocidad), aunque permite que empresas extranjeras instaladas en Chile operen sin restricción. Un argumento utilizado en la industria doméstica contra la liberalización del cabotaje interno en forma unilateral es que las empresas extranjeras entrarían al mercado en el período de punta y lo abandonarían en el período fuera de punta. El argumento es que las empresas extranjeras, si se les permitiera el cabotaje doméstico, podrían ingresar naves durante el período de punta nacional (y de baja demanda internacional), ya que su costo alternativo es bajo. Con eso, las empresas domésticas sólo podrían competir reduciendo sus precios, por lo que finalmente los precios

${ }^{42}$ Sugerencia de C. Agostini, que agradezco.

${ }^{43}$ Para determinar la viabilidad de un estudio con estas características, se ha realizado una encuesta piloto con buenos resultados. 
serían los de competencia en el período de punta. Durante la temporada baja nacional (y alta internacional), las empresas extranjeras sacarían sus aviones, pero el período de baja no es rentable para las aerolíneas domésticas. Por lo tanto, los beneficios que obtienen los usuarios en los períodos de punta por la entrada de operadores estacionales se perderían durante el resto del año. Peor aún, las empresas domésticas afirman que el servicio en el período fuera de punta empeoraría.

Según ellas, si el cabotaje doméstico está cerrado a naves extranjeras, durante el período de punta pueden obtener mayores ingresos por vuelo, lo que les permite ofrecer un servicio de buena calidad el resto del año. El argumento, por lo tanto, consiste en que las empresas aéreas cobran un precio por sobre el competitivo en el período de alta demanda, y luego utilizan los ahorros generados para subsidiar las frecuencias en el período fuera de punta. Ésta sería, por lo tanto, una política similar a la aplicada en las autopistas concesionadas o en el Metro. Al dejar de recibir rentas durante el período de punta, debido a la entrada de competencia extranjera en cabotaje, las empresas domésticas tendrían que reducir su frecuencia en el período fuera de punta, lo que empeoraría el servicio.

Aunque a primera vista este argumento puede parecer razonable, no lo es tanto. El problema es que no da cuenta de la flexibilidad para contratar aeronaves en el mercado internacional. Las empresas domésticas pueden contratar aviones en el mercado internacional durante el período fuera de punta del Norte (cuando hay sobreoferta) que es el de punta en Chile, y devolverlos en el período fuera de punta. Si las empresas nacionales usaran esa estrategia, que es lo que haría cualquier empresa eficiente, las frecuencias fuera de punta serían las mismas que si se abriera el cabotaje a extranjeros. En tal caso, los usuarios no percibirían beneficios en período fuera de punta y estarían peor en período de punta al prohibirse el cabotaje a firmas extranjeras.

Segundo, de ser válido el argumento, indicaría que no existe competencia en el mercado interno. La única manera en que las empresas domésticas podrían tener rentas durante el período de punta es que no sea fácil para entrantes domésticos traer aviones para atender la temporada de punta. De lo contrario, volveríamos al caso en que, al no haber rentas en el período de punta, tampoco es posible realizar transferencias al período fuera de punta.

En conclusión, no parecen defendibles los argumentos utilizados por las empresas domésticas para sostener la conveniencia de prohibir el cabotaje por firmas extranjeras. Más aún, podría ser recomendable estudiar cuáles son las razones que entraban la entrada de firmas domésticas y explican que, aparentemente, las empresas domésticas obtienen rentas en el período de punta. 


\section{B. Planilla de cálculos de Maple}

Cálculos bienestar JAC

> eps:=2.5;Pmax:=15000;Rdom:=.77; \#Parámetros de entrada. Rdom es fracción doméstica.

eps := 2.5

Pmax := 15000

Rdom := 0.77

$>$ solve(q-a* $\mathrm{p}^{\wedge}($-épsilon),p);

$$
e^{-\ln \left(\frac{q}{a}\right) \varepsilon^{-1}}
$$

> CS:=int(exp(-ln(v/a)/épsilon),v); \# Integral que da el bienestar del consumidor.

$$
C S:=v \varepsilon e^{-\ln \left(\frac{v}{a}\right) \varepsilon^{-1}}(\varepsilon-1)^{-1}
$$

> alf:=q/p^(-épsilon);

$$
\text { alf }:=\frac{q}{p^{-\varepsilon}}
$$

> Qobs:=152783;Pobs:=904;\#Parámetros de demanda.

$$
\text { Qobs := } 152783
$$

Pobs := 904

> alpha:=subs(q=Qobs,p=Pobs,épsilon=eps,alf); \# Determinación de la constante de la demanda.

$>\mathrm{Q}:=$ alpha*P^(-épsilon);

$$
\alpha:=3754015916000.0
$$

> Qmin:=evalf(subs(épsilon=eps,P=Pmax,Q)); \# Cálculo de viajes correspondientes a Pmax. Qmin := 136.2284960

> B:=evalf(subs(v=Qobs,épsilon=eps,a=alpha,CS)- $\operatorname{subs(v=Qmin,épsilon=eps,a=alpha,CS))*Rdom;~}$ \# Bienestar del consumidor.

$>$ A:=(Pmax-Pobs)*Qmin*Rdom;

$B:=174626252.4$

$A:=1478613.198$

> cost:=Pobs*(épsilon-1)/épsilon;

$$
\text { cost }:=904 \frac{\varepsilon-1}{\varepsilon}
$$

> c:=subs(épsilon=eps,cost);

$>$ C: $=($ Pobs-c)*Qobs*Rdom; \#Utilidades firma doméstica

$$
c:=542.4000000
$$

$>\mathrm{W}:=\mathrm{A}+\mathrm{B}+\mathrm{C}$; \# Binenestar total

$$
C:=42539676.26
$$

> Bprime:=evalf(subs(v=Qobs+5200,épsilon=eps,a=alpha,CS) -subs(v=Qmin,épsilon=eps,a= alpha,CS))*Rdom;

> Cprime: $=($ Pobs-c)*(Qobs+5200)*Rdom;

Bprime := 178221613.0

> DeltaW:=(Cprime-C)+(Bprime-B);\#Cambio en bienestar.

DeltaW := 5043207.0

> DeltaB:=Bprime-B;DeltaC:=Cprime-C;

DeltaB $:=3595360.6$

DeltaC := 1447846.40 


\section{REFERENCIAS}

Agostini, Claudio (2005): "El Mercado de Transporte Aéreo: Lecciones para Chile de una Revisión de la Literatura”. Documento de Investigación I-163, Ilades-Georgetown.

Baumol, W. J., J. C. Panzar y R. D. Willig (1982): Contestable Markets and the Theory of Market Structure. San Diego: Harcourt Brace Jovanovich.

Berry, Steven, James Levinsohn y Ariel Pakes (1999): "Voluntary Export Restraints on Automobiles: Evaluating a Trade Policy”. En American Economic Review, 89 (3), junio, pp. 400-430.

BID (Banco Interamericano de Desarrollo) (2003): "Estudio de Integración del Transporte Aéreo en Sudamérica”. BID.

Brander, J. (1995): "Strategic Trade Policy”. En G. E. Grossman y K. Rogoff (eds.), Handbook of International Economics, Vol 3. Amsterdam: North-Holland, pp. 1395-1455.

Brander, J. y P. Krugman (1983): “A ‘Reciprocal Dumping’ Model of Internatiotal Trade”. En Journal of International Economics, 15: 313-323.

Brander, J. y B. E. Spencer (1985): "Export Subsidies and Market Share Rivalry”. En Journal of International Economics, 18: 83-100.

Dixit, A. (1986): “Comparative Statics for Oligopoly”. En International Economic Review, 27 (1): 107-122.

Dixit, A. K. (1987): “Trade and Insurance with Moral Hazard”. En Journal of International Economics, 23, 201-220.

Dixit, A. K. y V. Norman (1981): Theory of International Trade. Cambridge: Cambridge University Press,

Doganis, R. (1991): Flying Off Course: The Economics of International Airlines. Routledge, $2^{\text {a }}$ edición.

Eaton, J. y G. E. Grossman (1992): “Optimal Trade and Industrial Policy under Oligopoly”. En G. E. Grossman (ed.), Imperfect Competition and International Trade. Cambridge, MA: The MIT Press, pp. 121-140.

Gönenç, R. y G. Nicoletti (2001): "Regulation, Market Structure and Performance in Air Passenger Transportation”. En OECD Economic Studies No 32.

Grossman, G. E. (1992): Imperfect Competition and International Trade. The MIT Press.

Harris, R. (1985): "Why Voluntary Exports Restraints Are 'Voluntary””. En Canadian Journal of Economics, XVIII: 799-809.

Helpman, E. (1997): "Politics and Trade Policy”. En D. M. Kreps y K. F. Wallis (eds.), Advances in Economics and Econometrics: Theory and Applications, 5309. New York: Cambridge University Press, pp. 19-45, 34.

Krugman, P. (1987): "Intraindustry Specialization and the Gains from Trade”. En Journal of Political Economy, 87: 253-265.

Krugman, P. (1988, Fall): “Is Free Trade Passé”. En Journal of Economic Perspectives.

Krugman, P. R. (1981): "Intraindustry Specialization and the Gains from Trade”. En Journal of Political Economy, 89 (5): 959-973.

JAC (Junta de Aeronáutica Civil). http://www.juntadeaeronauticacivil.cl/.

Morrison, S. A. y C. Winston (1987): "Empirical Implications and Tests of the Contestability Hypothesis”. En Journal of Law and Economics, 30 (1): 53-66.

Stigler, G. (1971): “The Theory of Economic Regulation”. En The Bell Journal of Economics and Management Science, 2 (1): 3-21, 35.

The Economist (2006): “The Sky is the Limit”. Junio 8. 